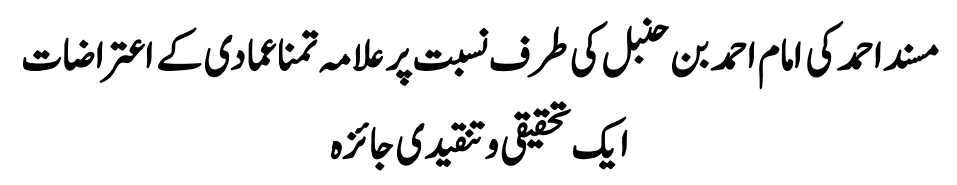

\title{
Allama Tamanna Imadi Objections in the Attribution of "Musnad Ahmad" to Imam Ahmad bin Hanbal (Critical and Research Study)
}

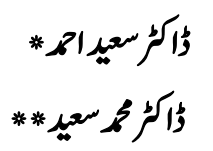

ISSN (P) 2664-0031 (E) 2664-0023

DOI: https://doi.org/10.37605/fahmiislam.v4i1.228
Received: January 13,2021

Accepted: February 22, 2021

Published: June 30,2021

\begin{abstract}
This research article studies the objections of Allama Tamanna Imadi in the attribution of "Musnad Ahmad" to Imam Ahmad bin Hanbal and that its narrators are unreliable. He denies the authenticity of Musnad Ahmad bin Hanbal, which is the largest collection of hadiths of the Holy Prophet Peace and blessing of Allah be upon him. He has raised some objections from which the first objection is that: the attribution of "Musnad Ahmad" to Imam Ahmad bin Hanbal is not correct because this book was presented by few conspirators as an alternate of the Holy Quran after the death of Imam Ahmad, for keeping agreed the followers of various sects and school of thoughts Muslim community. In addition, Tamanna Imadi has tried to prove that all the narrators of this book are unknown and unreliable having no sufficient value in the views of the scholars of Ilm ur Rijaal, Hadith and its sciences. In this research paper, we had tried to analyze critically the objections raised by Tamana Imadi in the light of the saying of prominent Scholars, Muhaditheen and experts of Hadith and Ilm ur Rijaal through which the actual situation of his objections has been exposed which is, that Musnad Ahmad is the book of Imam Ahmad and his narrators are reliable authentic.
\end{abstract}

Keywords: Musnad Ahmad, Imam Ahmad bin Hanbal, Allama Tamanna Imadi, Objections. 


\section{م)}

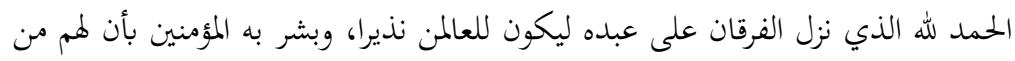

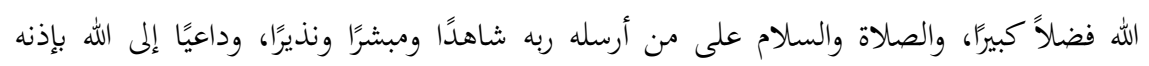

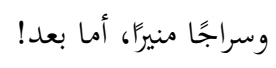

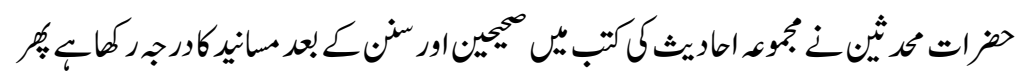

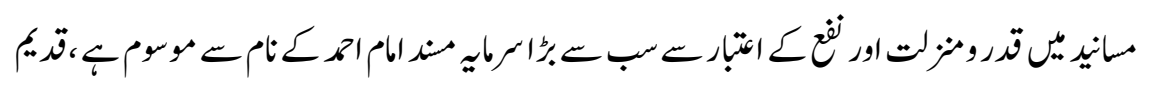

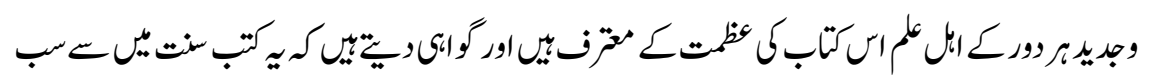

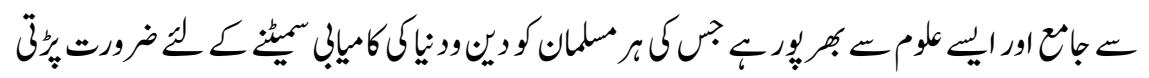

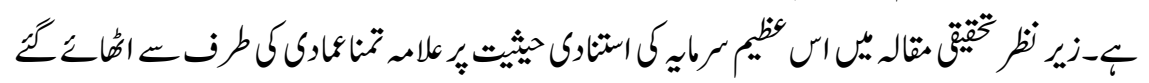

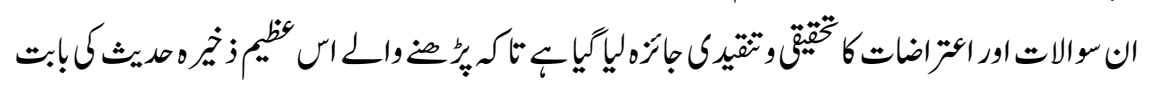

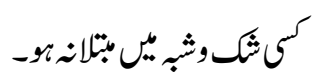

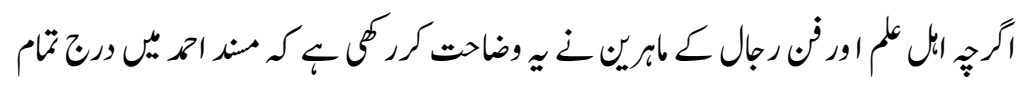

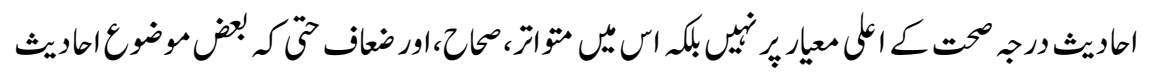

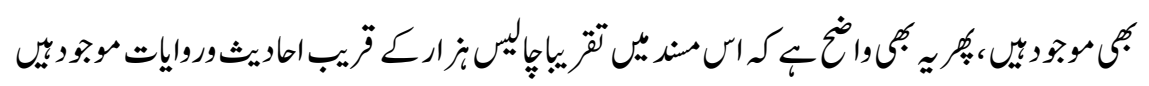

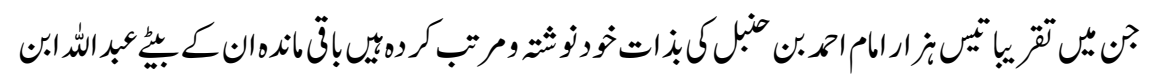

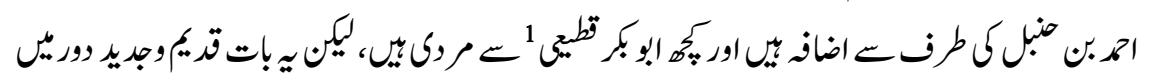

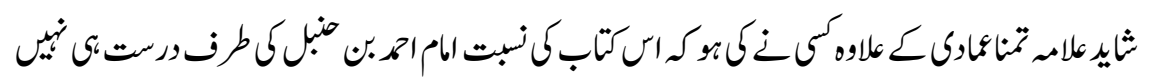

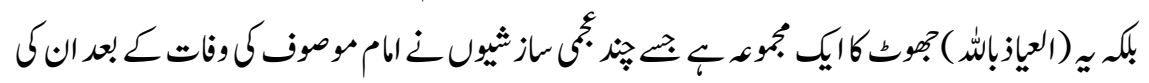

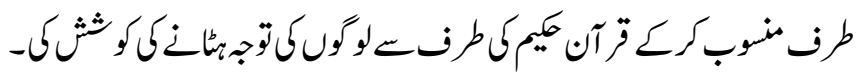

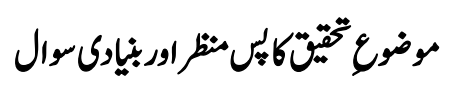

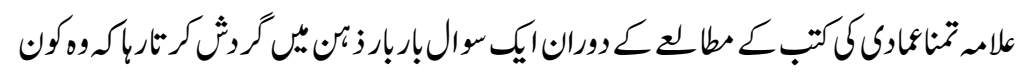

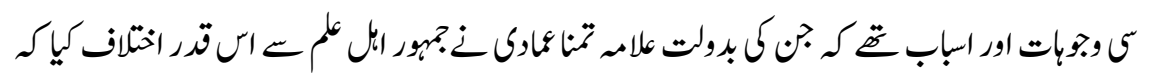

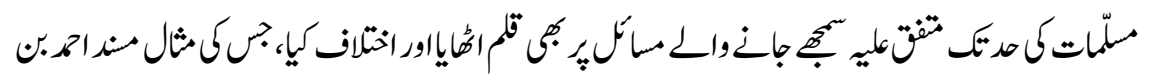




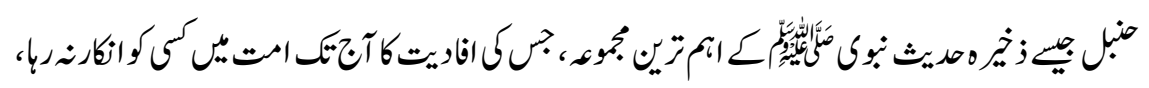

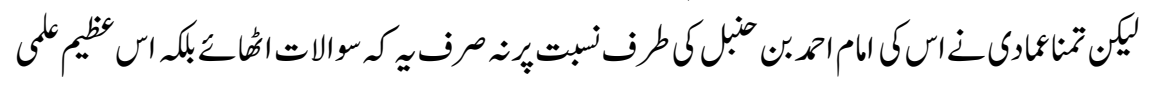

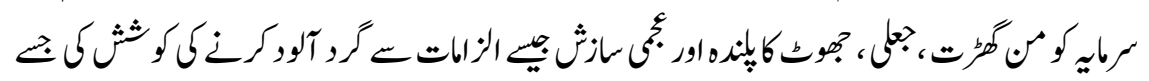

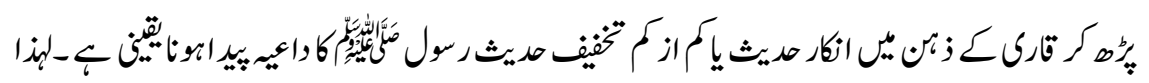

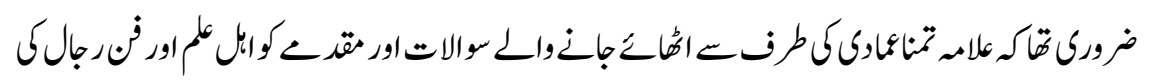

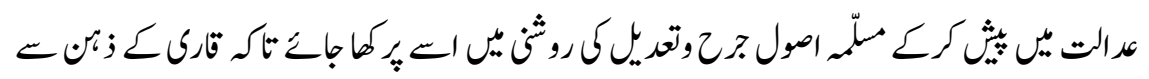

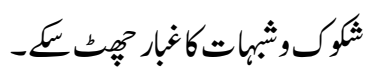

ثنج تحتين

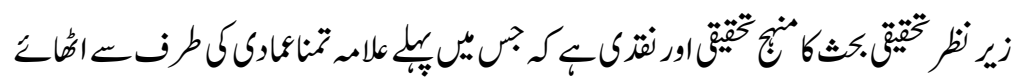

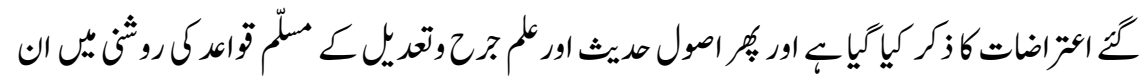

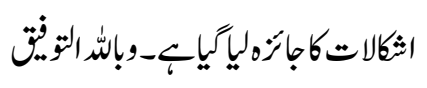

\section{علام تمناعماوك6 كثمر تحارف}

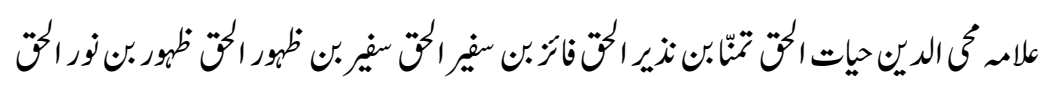

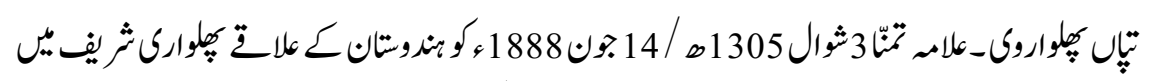

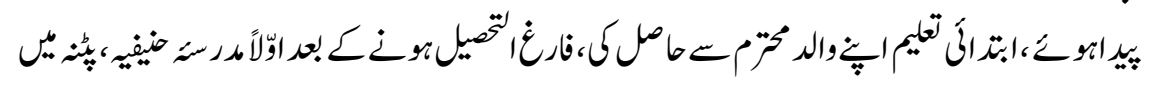

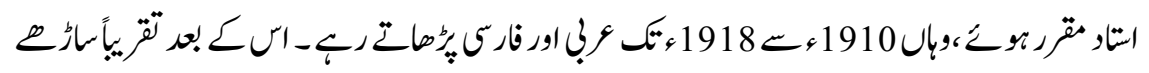

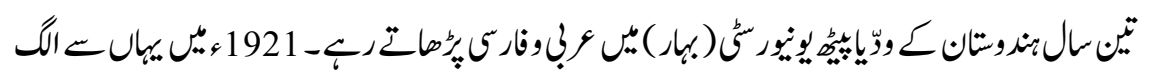

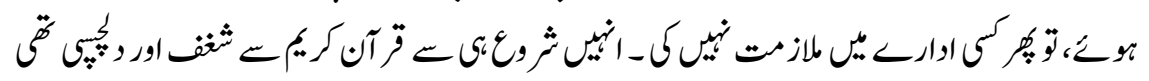

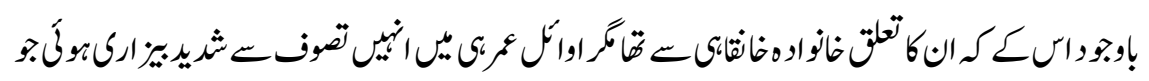

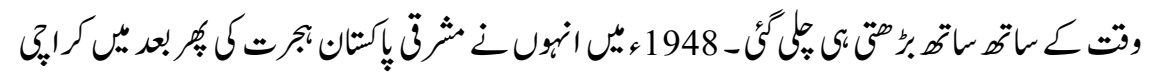

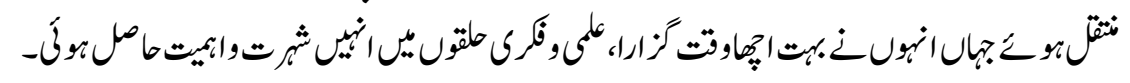

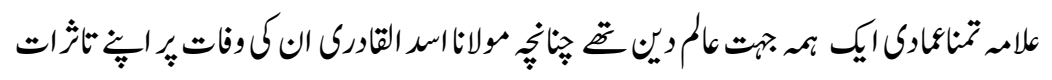

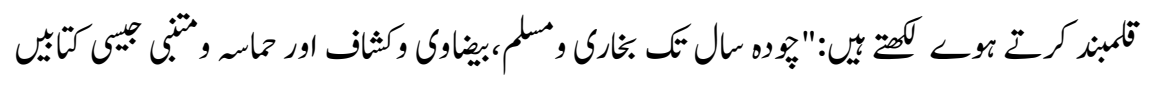




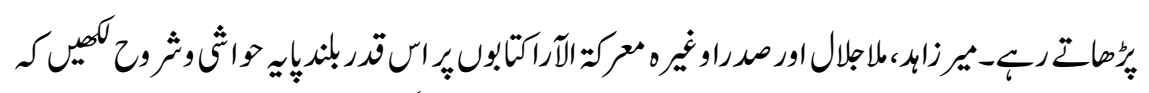

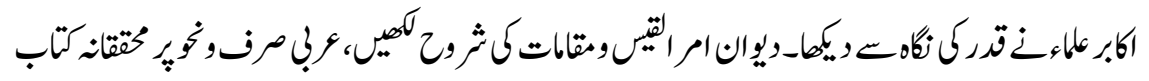

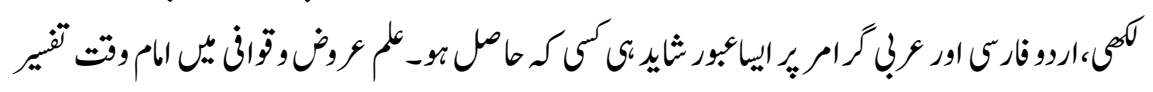

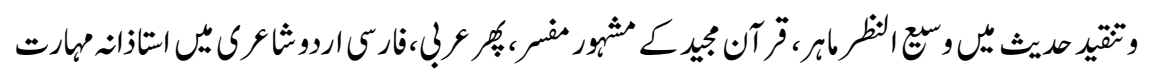

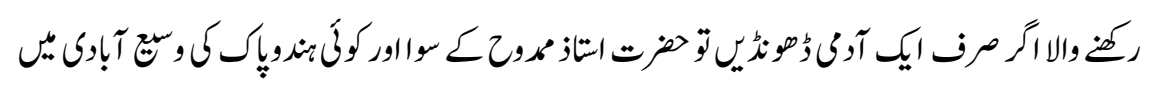

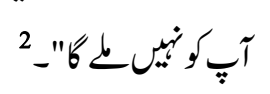

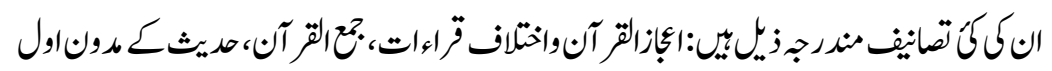

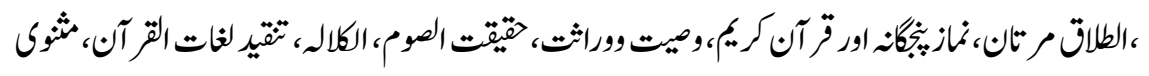

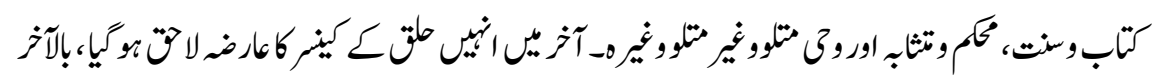

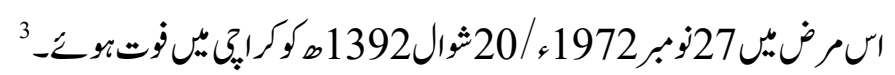

علامه تمناعماركاور م-ندامر

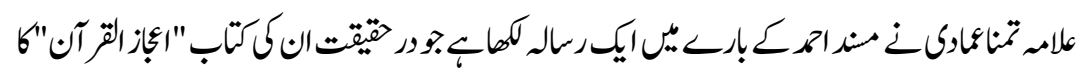

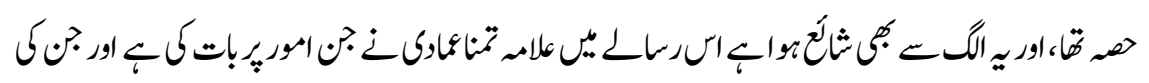

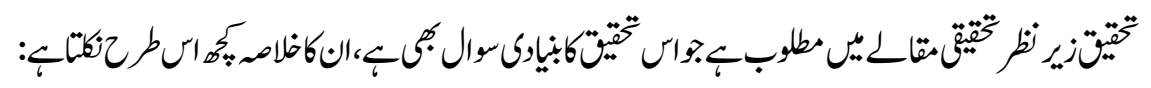
1)

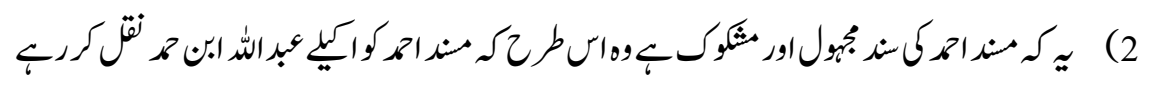

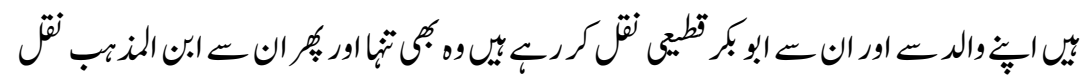

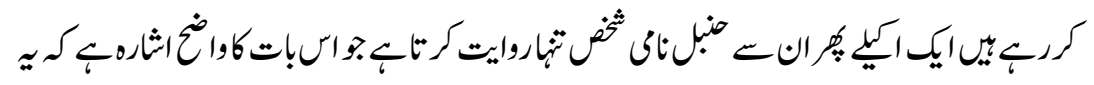

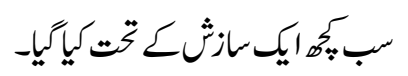

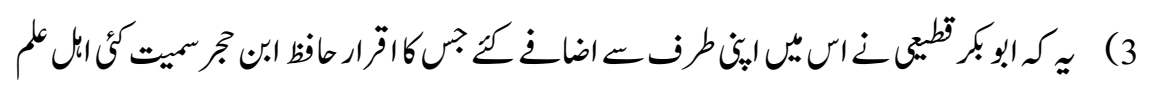

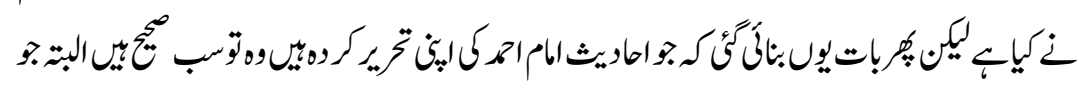

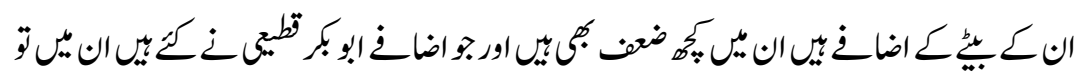

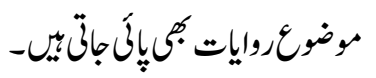




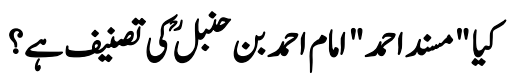

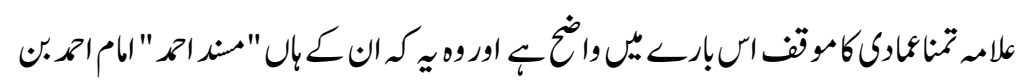

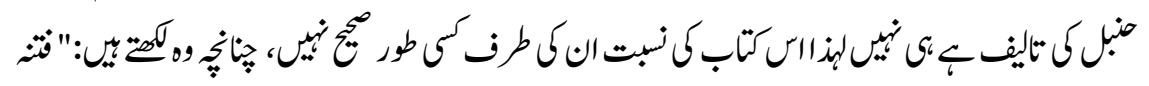

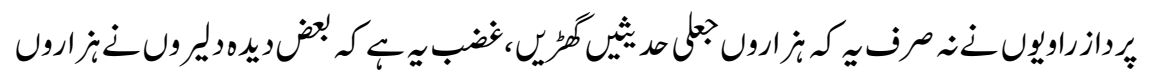

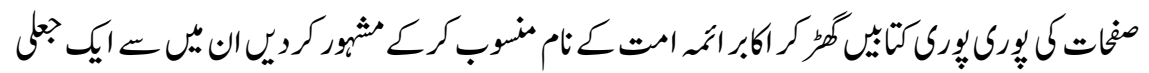

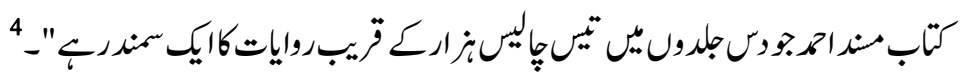

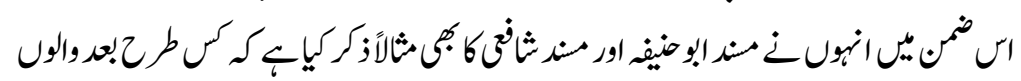

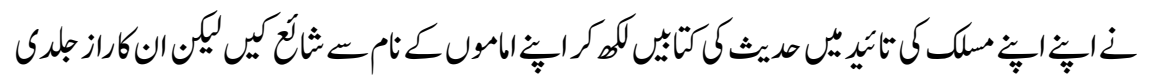

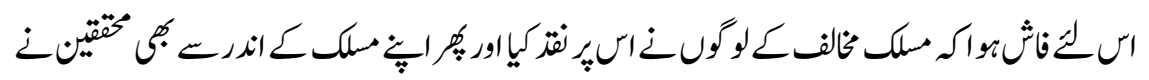

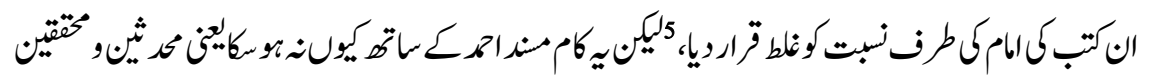

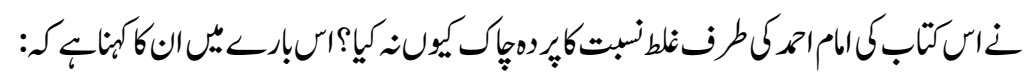

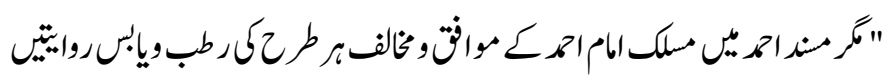

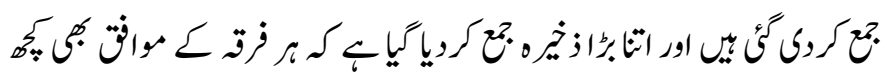

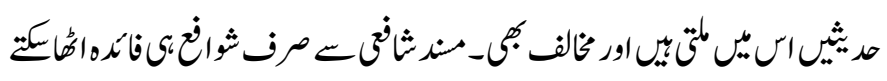

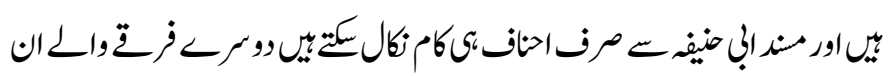

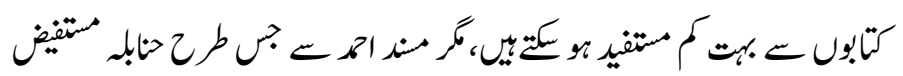

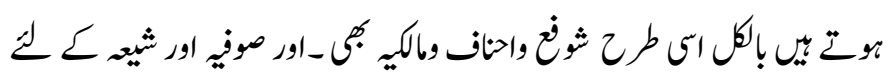

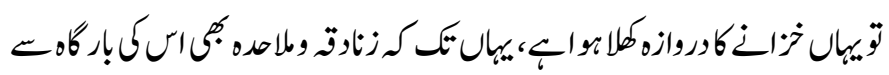

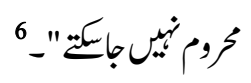

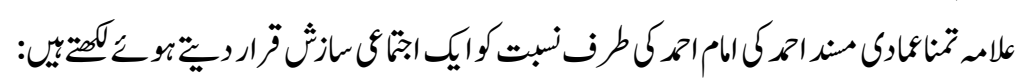

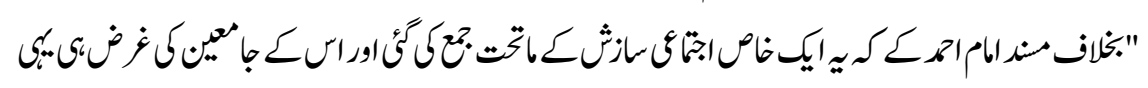

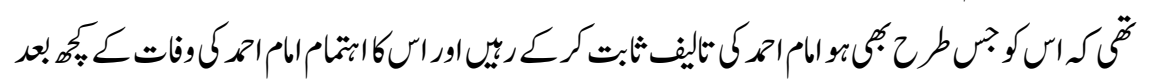

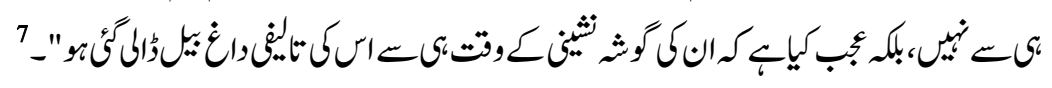




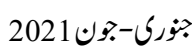

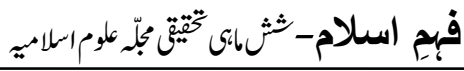

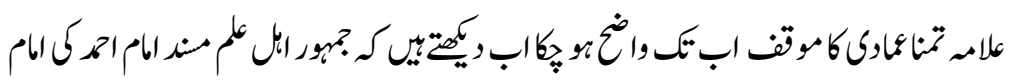

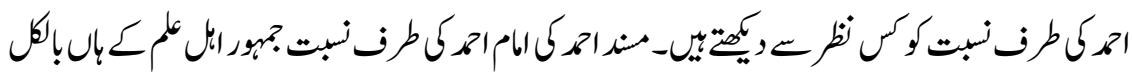

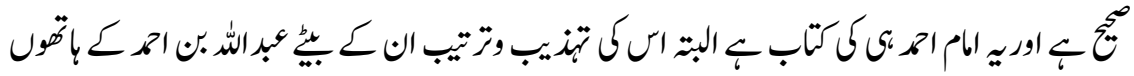

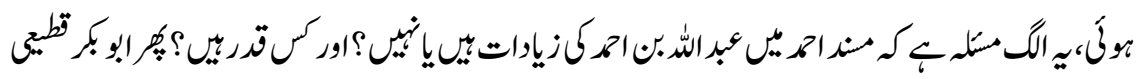

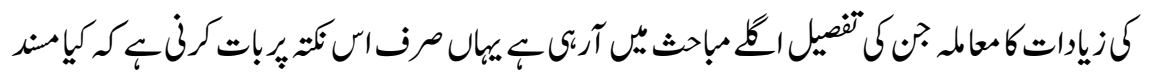

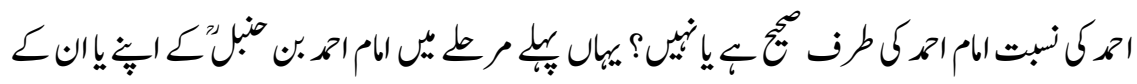

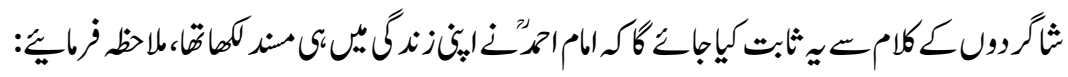

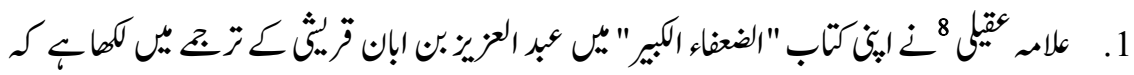

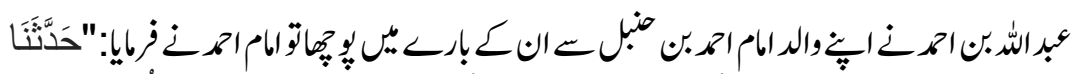

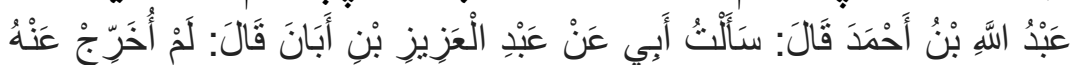

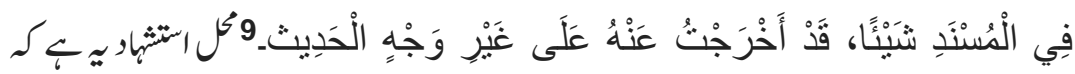

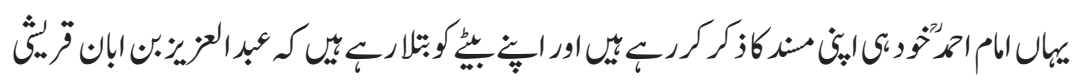

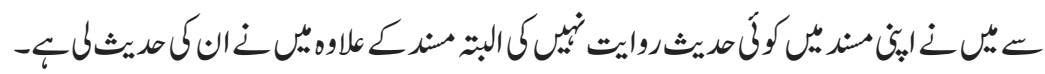

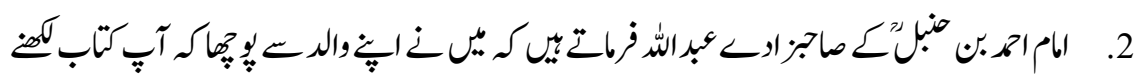

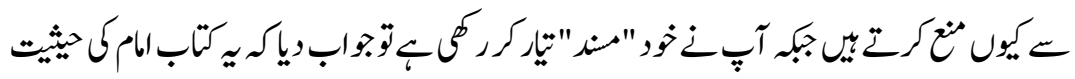

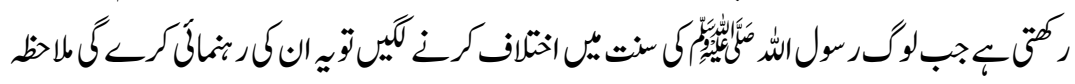

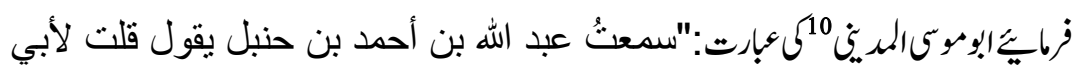

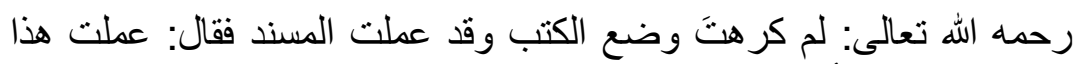

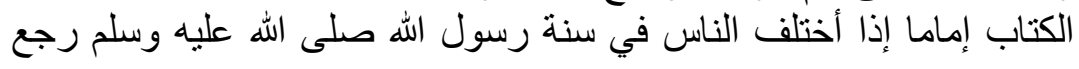

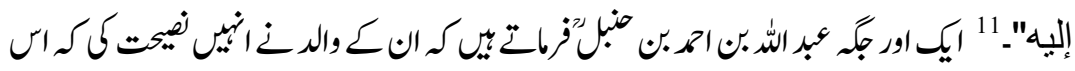

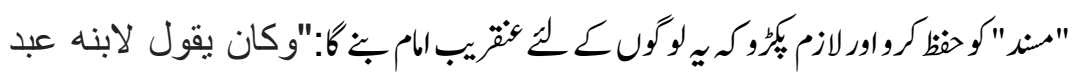

الله: احتفظ بهذا المسند فإنه سَيكون للناس إماماً". 12

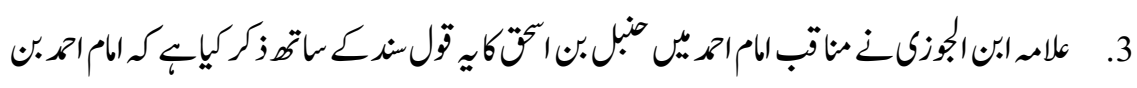

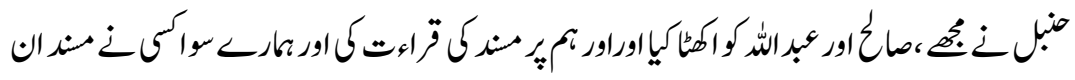

6 


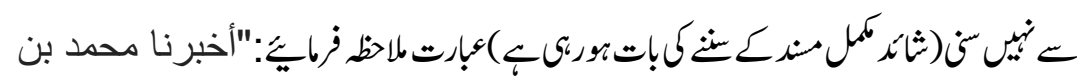

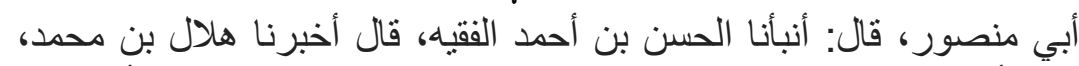

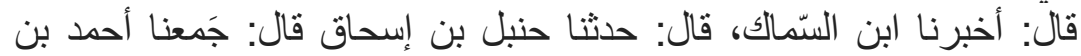

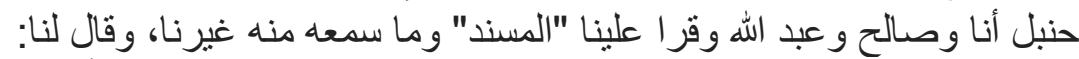

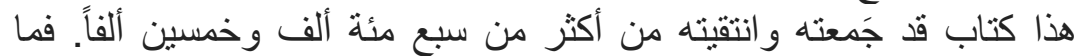

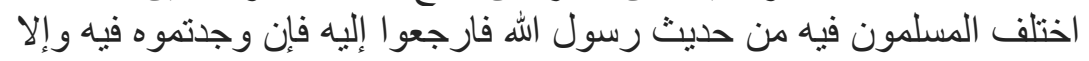

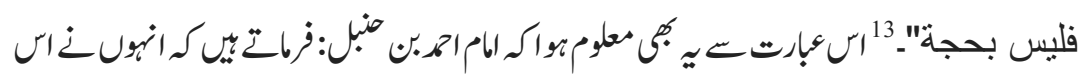

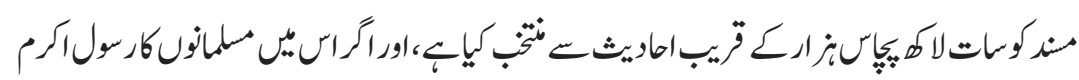

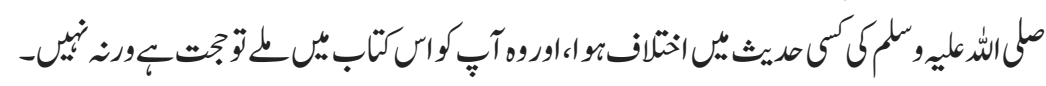

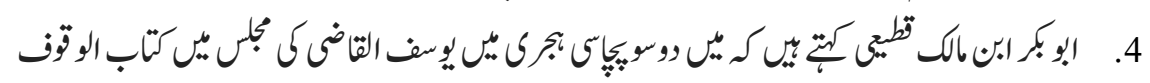

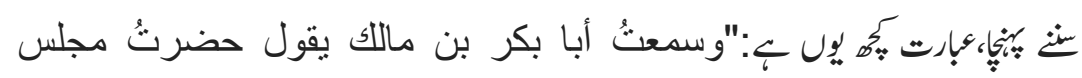

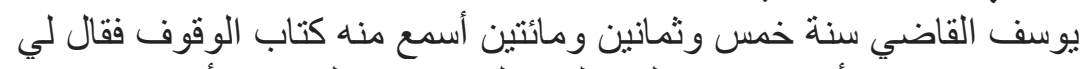

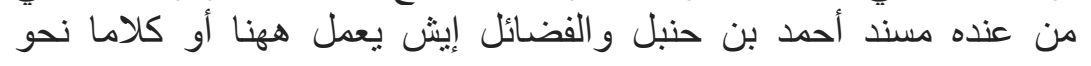

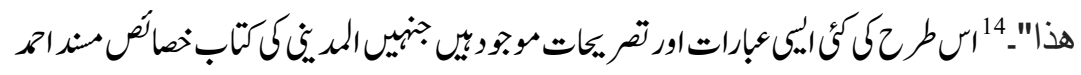

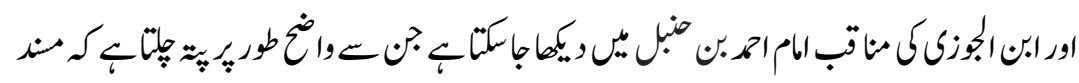

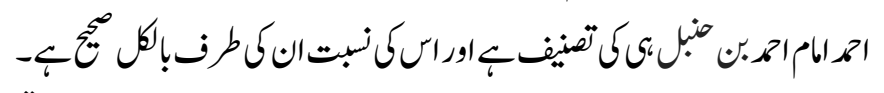

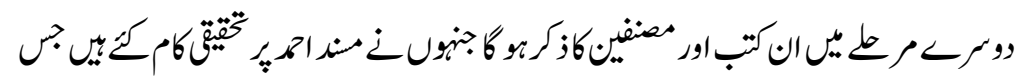

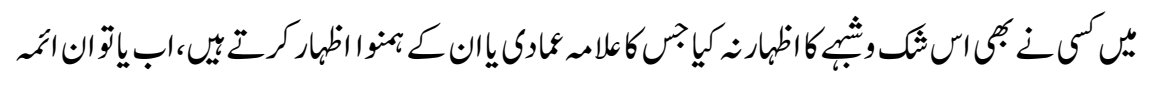

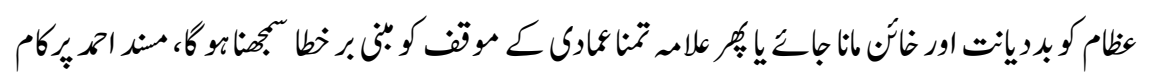

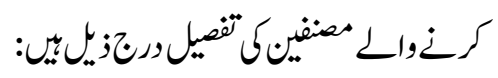

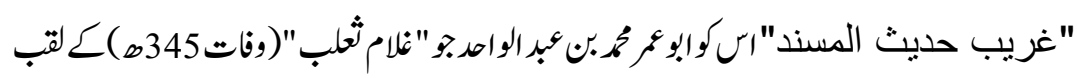

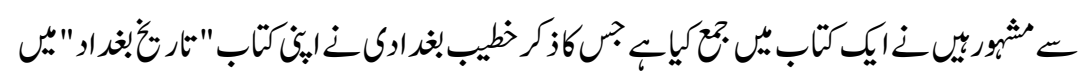

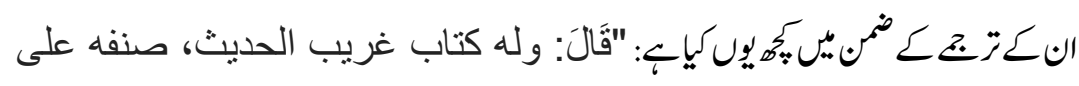

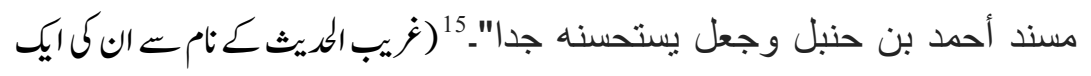

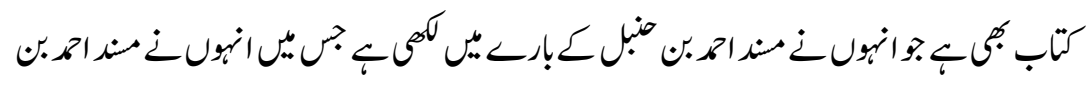

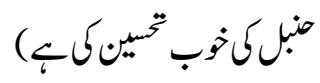


"ترتيب اسماء الصحابة اللذين في المسند على المعجم":يحثابعلامه ابن عساكرك

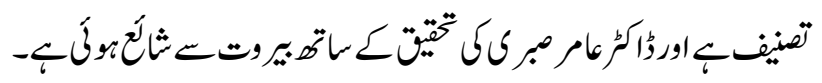

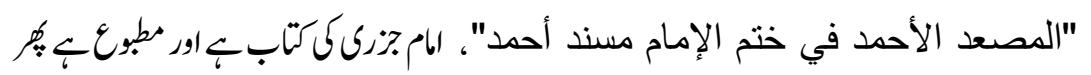

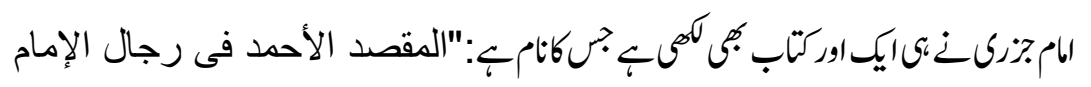
مسند".16

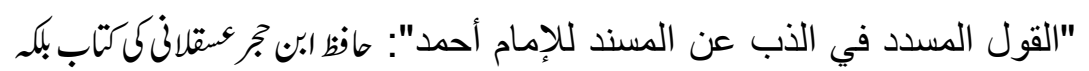

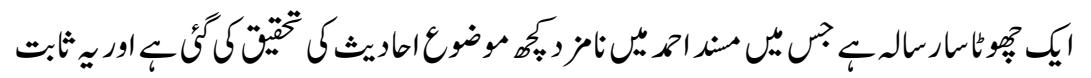

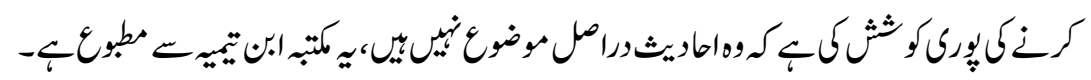

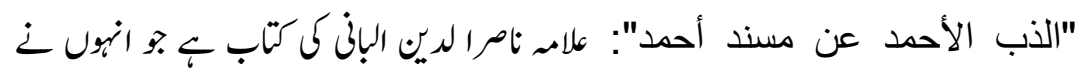

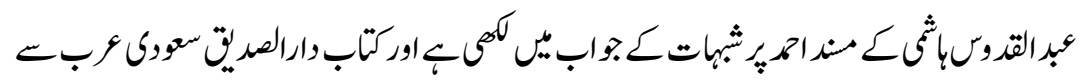

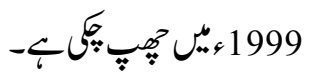

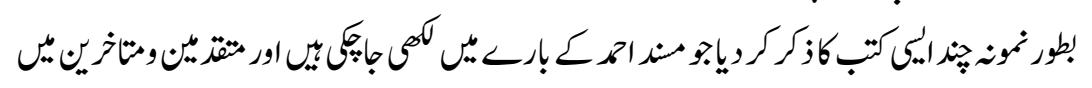

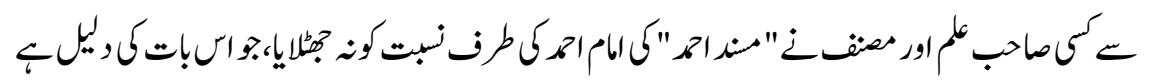

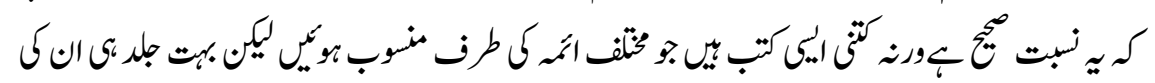

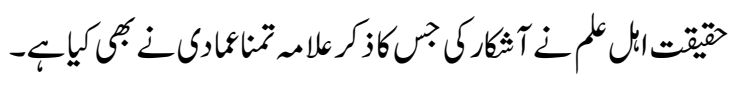

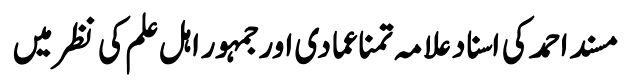

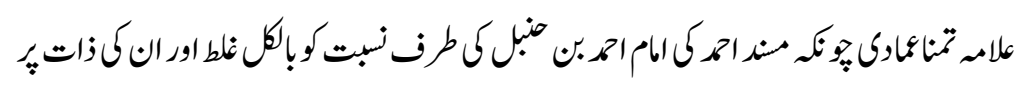

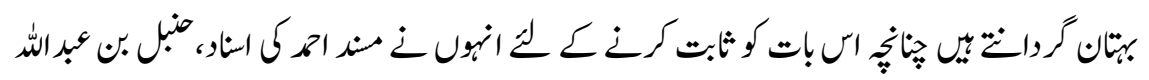

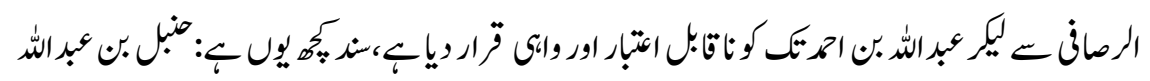

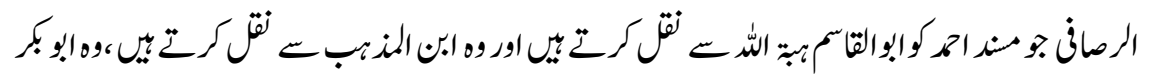

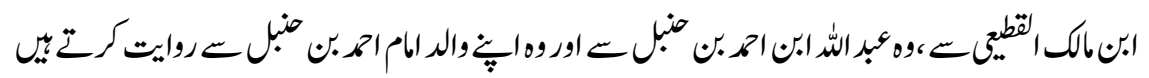

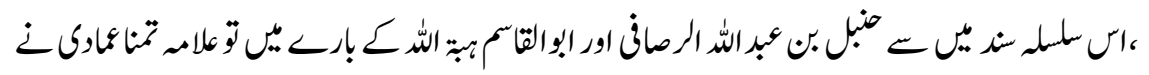

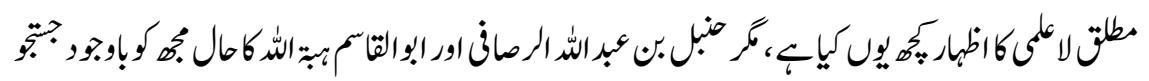




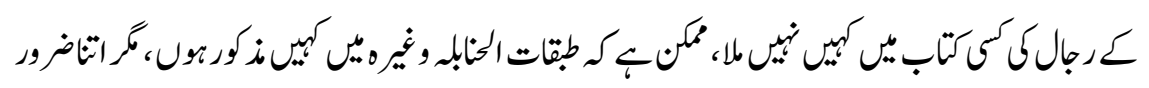

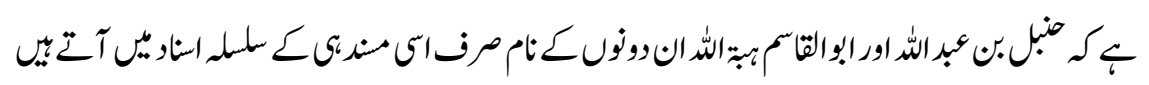

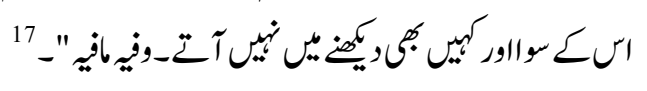

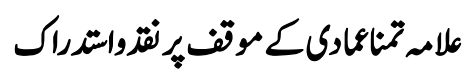

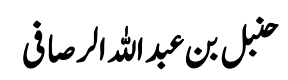

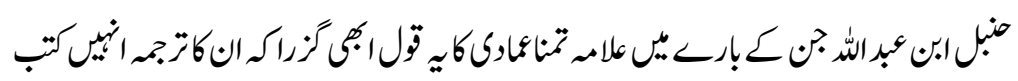

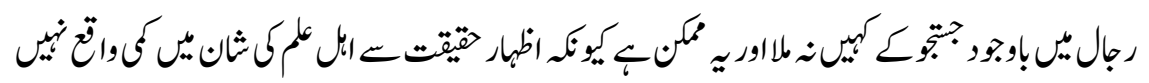

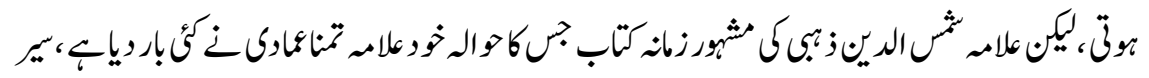

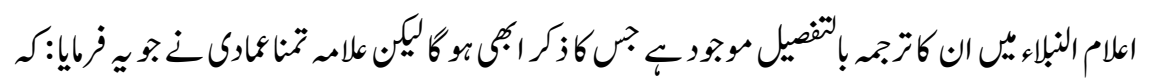

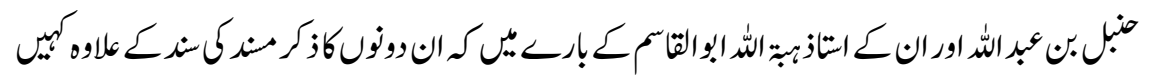

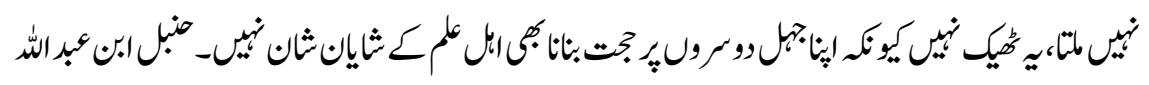

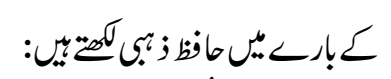

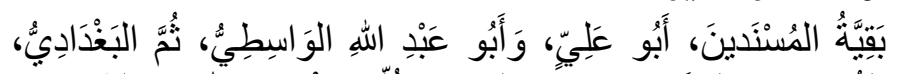

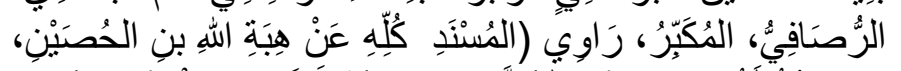

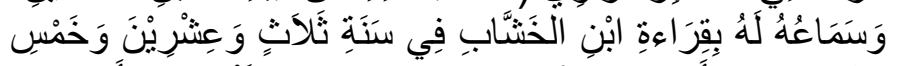

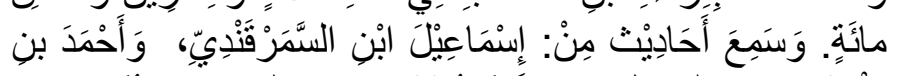

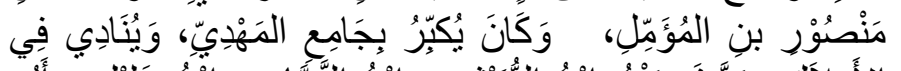

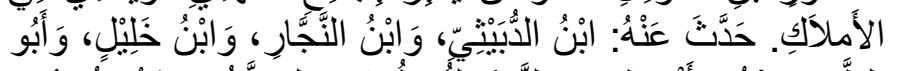

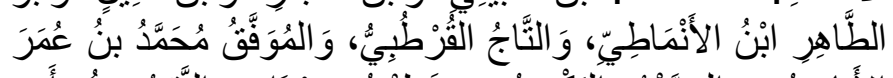

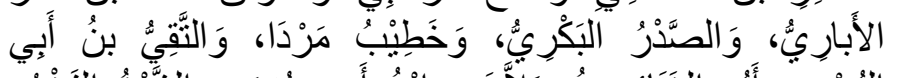

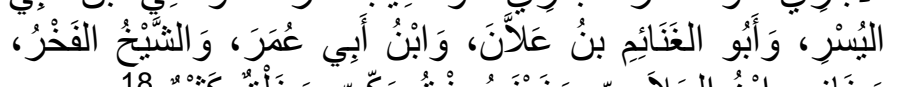

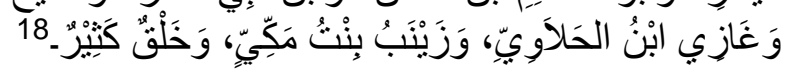

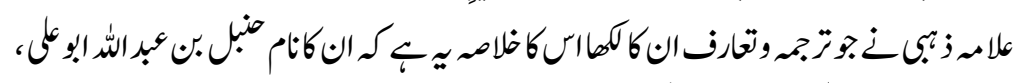

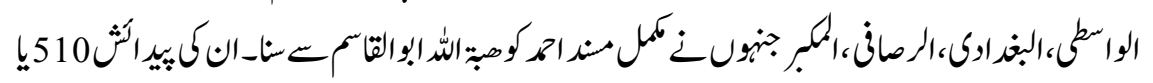

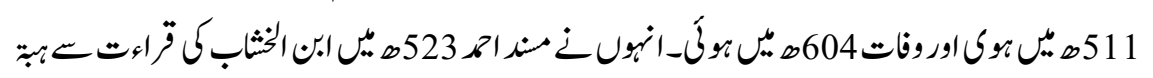

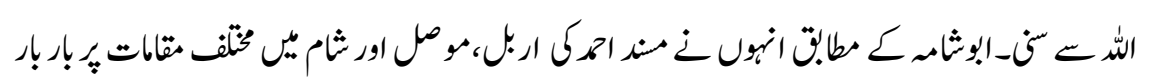




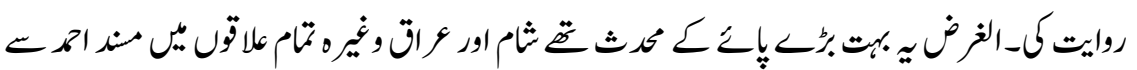

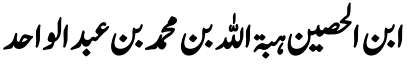

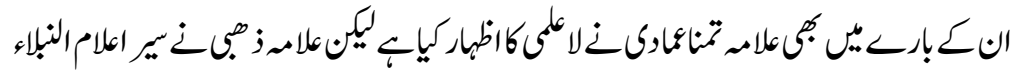

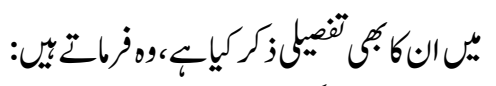

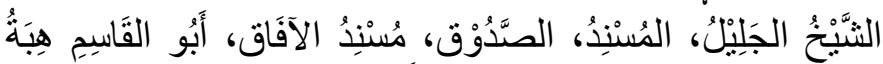

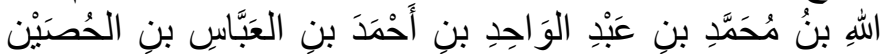

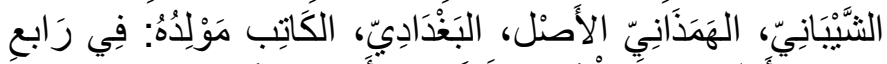

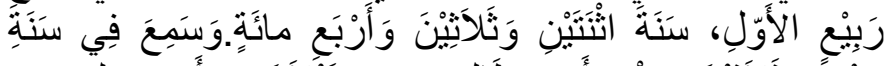

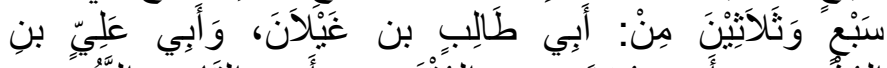

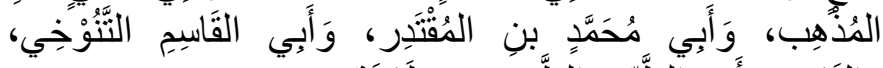

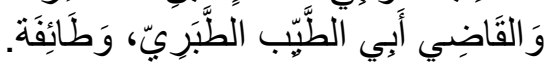

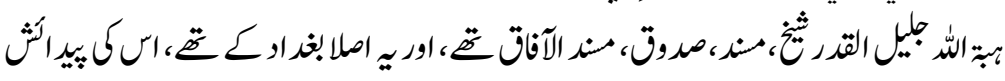

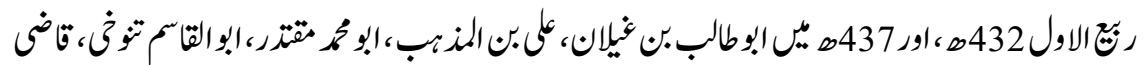

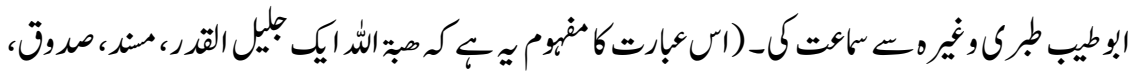

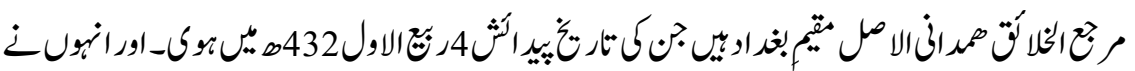

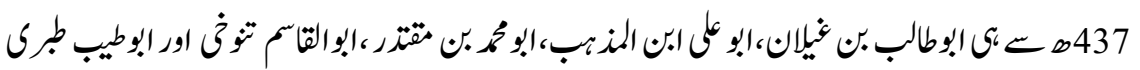

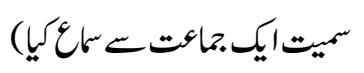

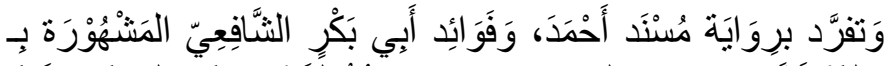

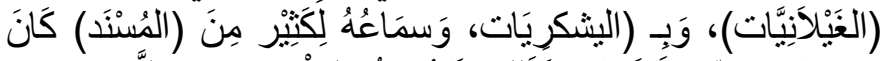

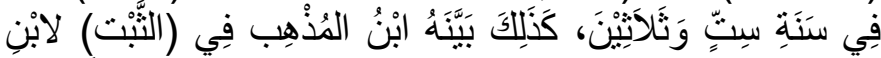

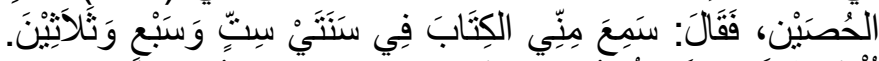

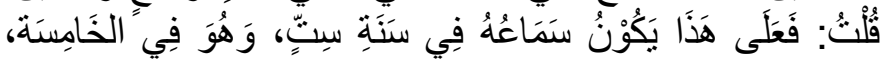

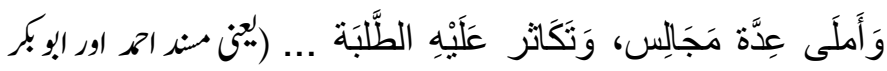

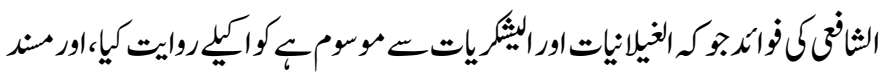

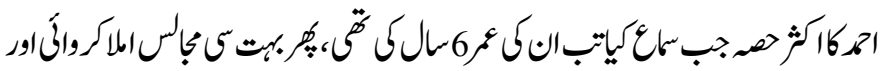

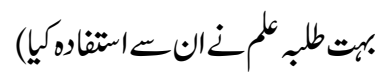




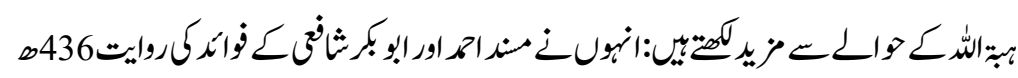

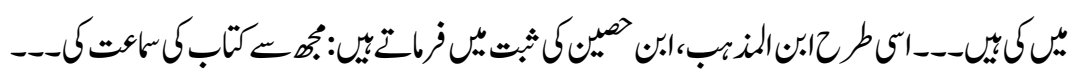

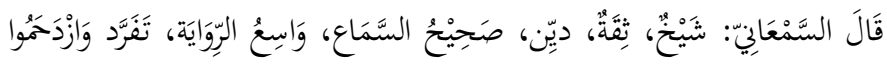

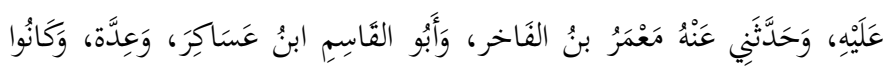

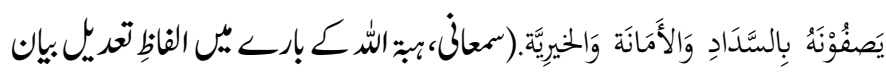

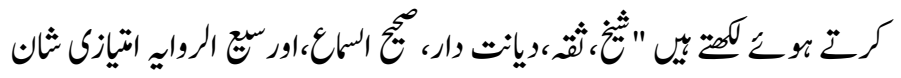

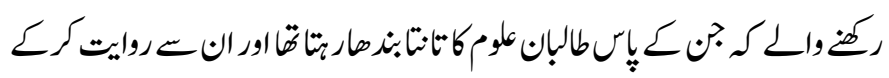

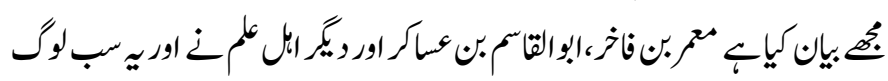

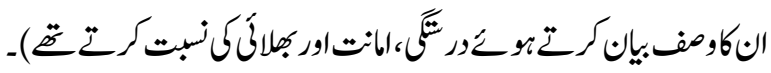

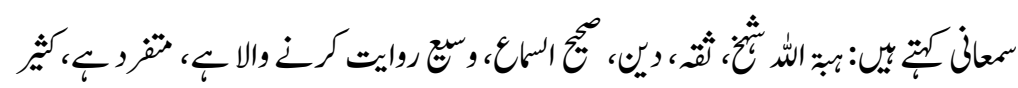

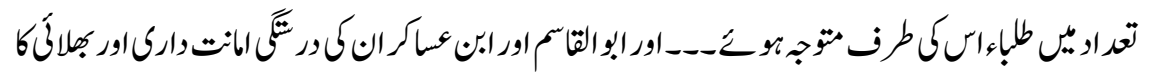

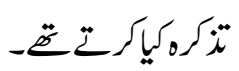

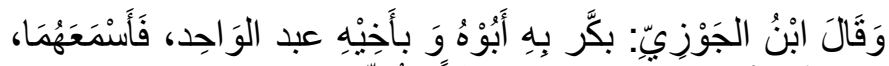

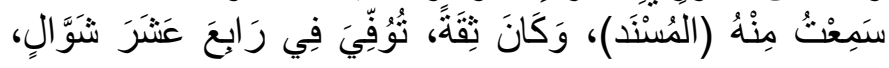

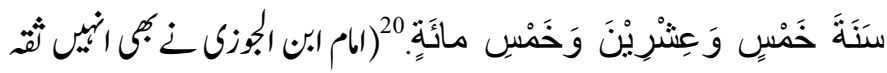

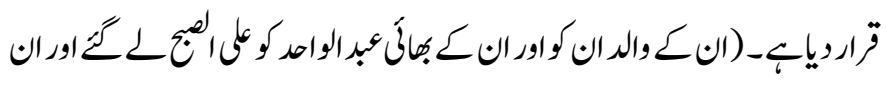

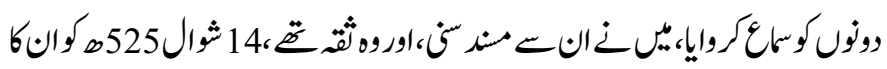

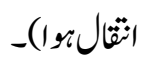

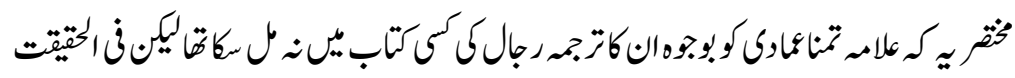

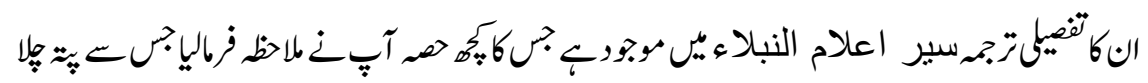

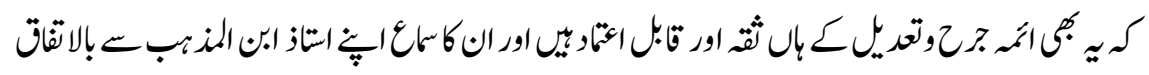

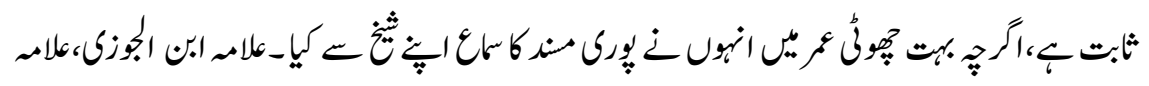

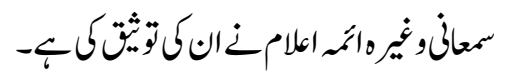

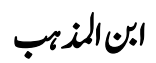




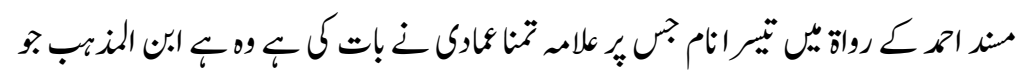

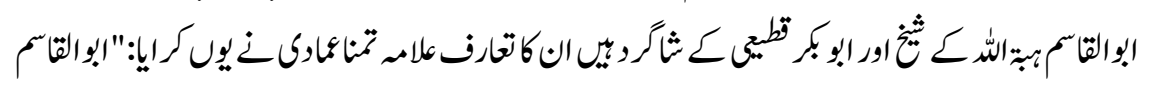

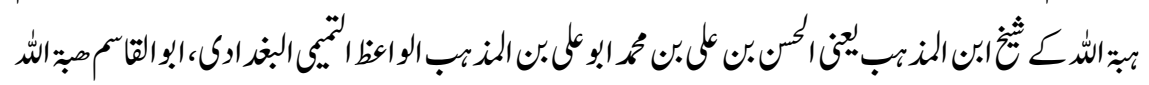

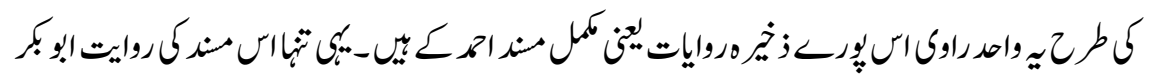

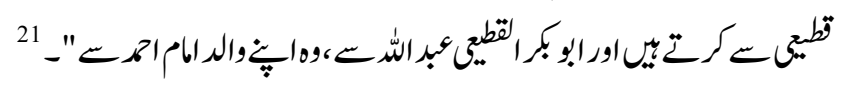

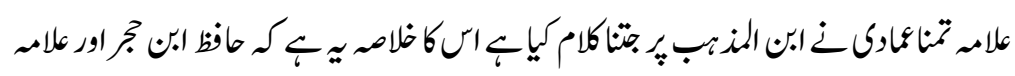

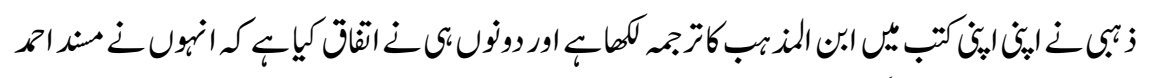

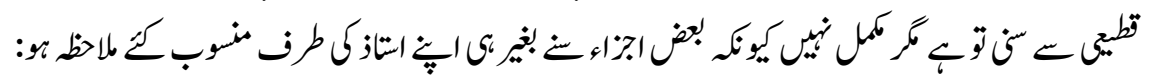

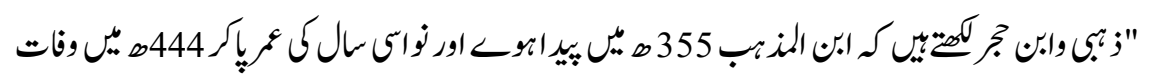

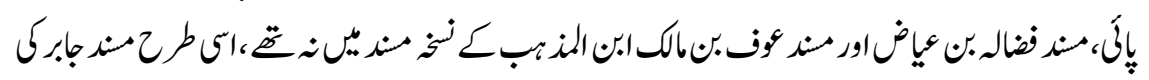

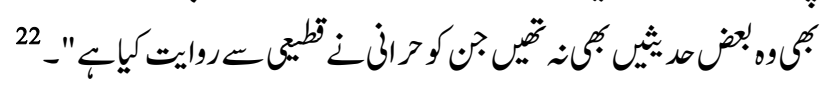

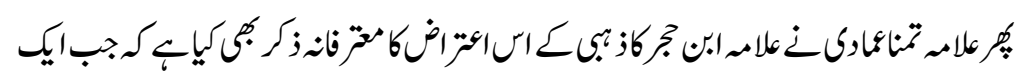

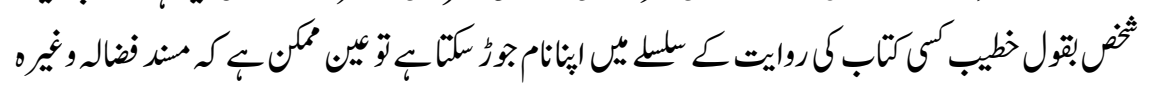

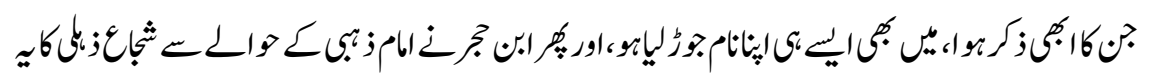

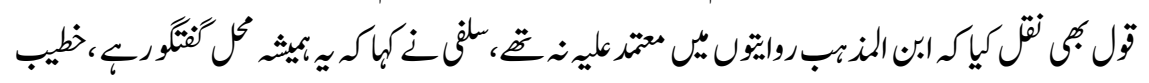

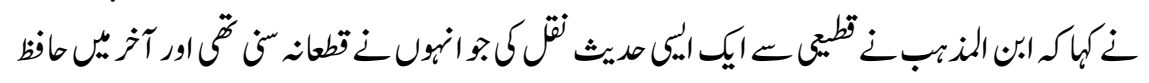

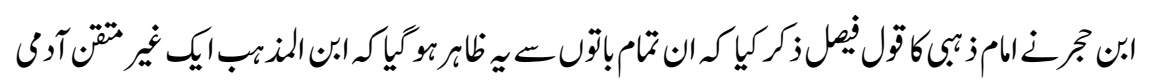

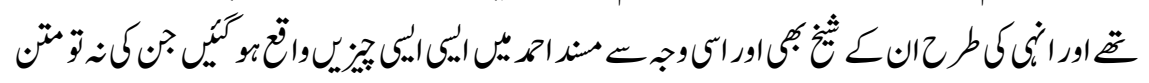

$$
23
$$

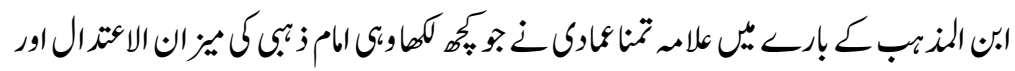

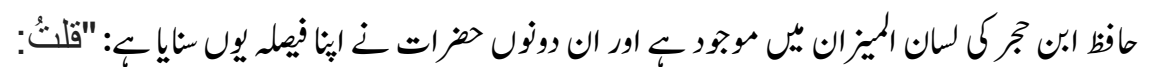
الظاهر من ابن المذهب أنه شيخ ليس بالمتقن، وكذللك شيخه ابن ماللك، ومن ثمان

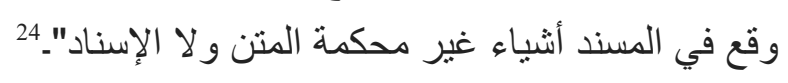

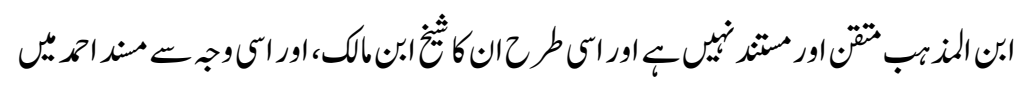




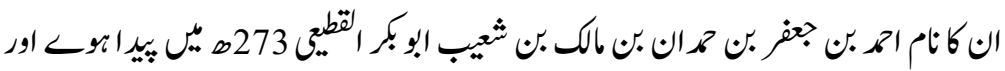

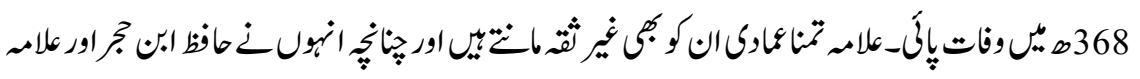

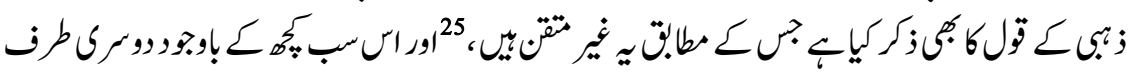

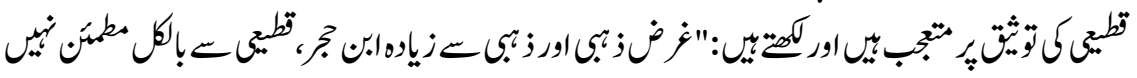

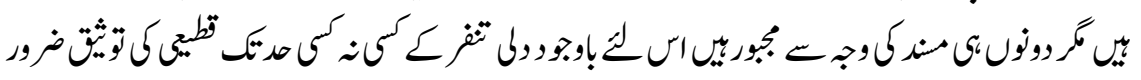

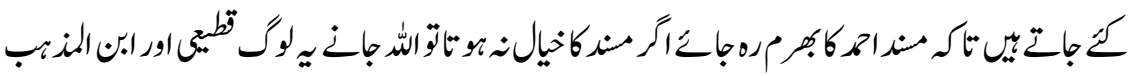

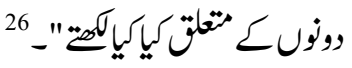

ابو بمرالشافى

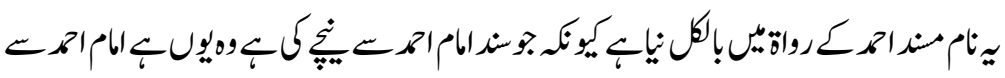

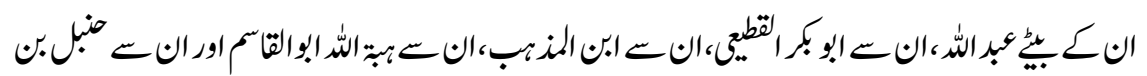

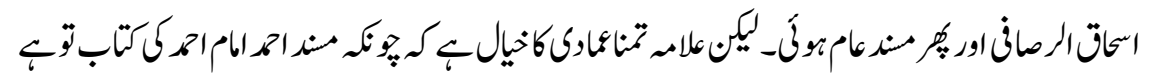

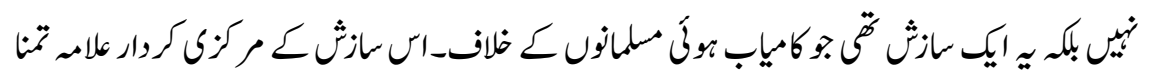

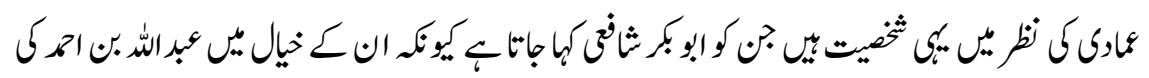

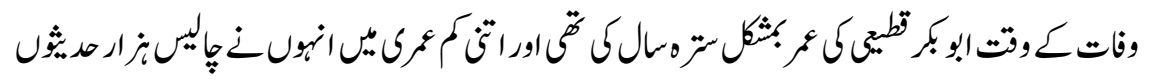

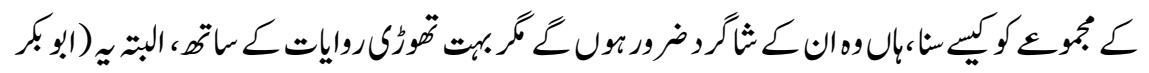

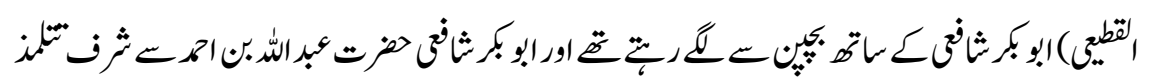

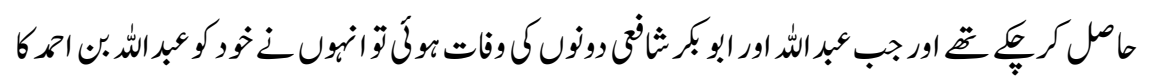

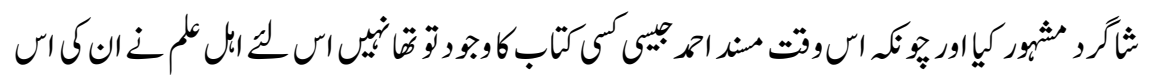

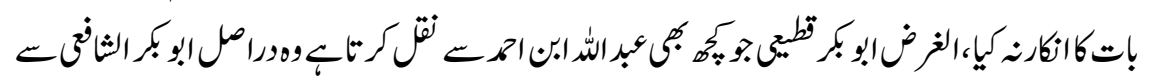

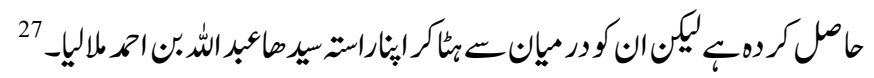

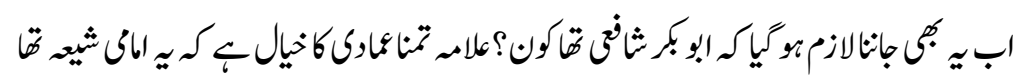

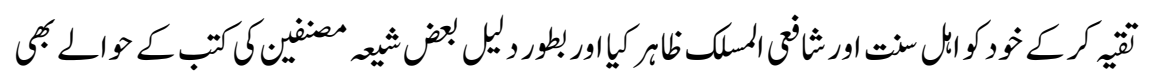

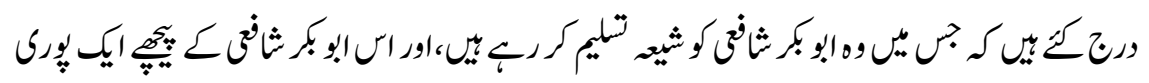




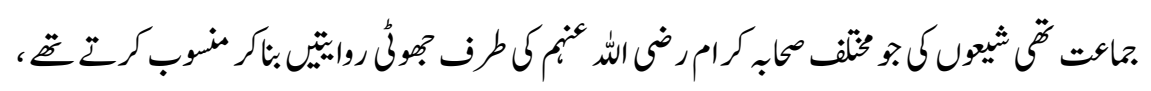

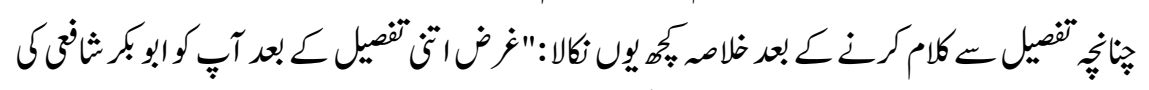

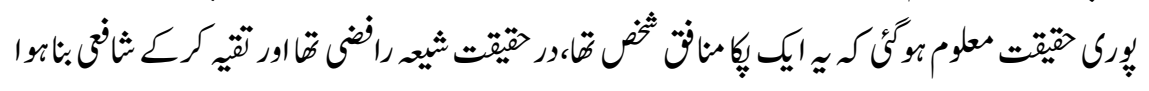

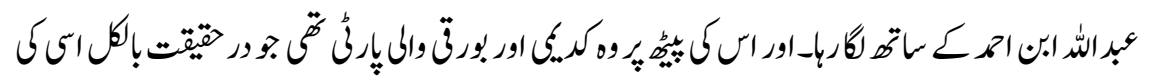

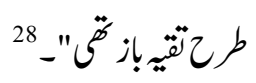

\section{نتزواتتراك}

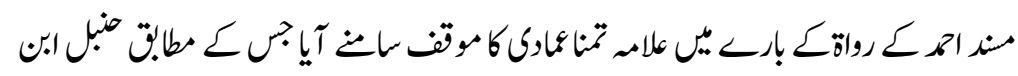

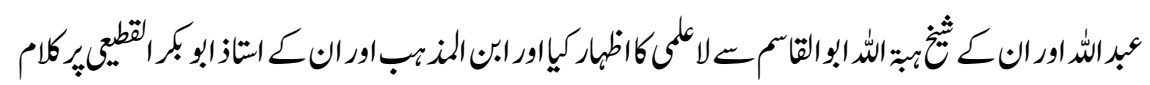

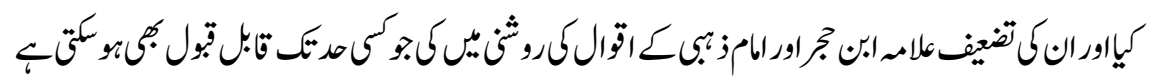

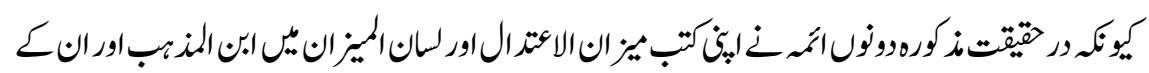

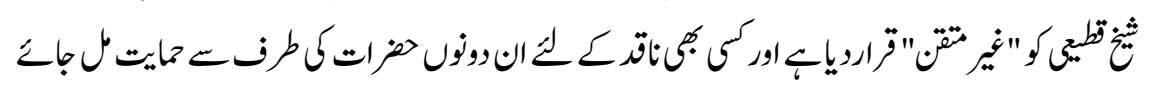

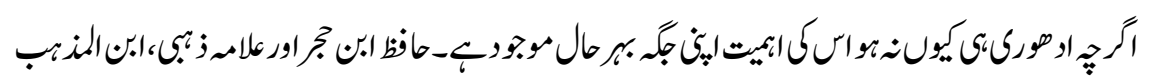

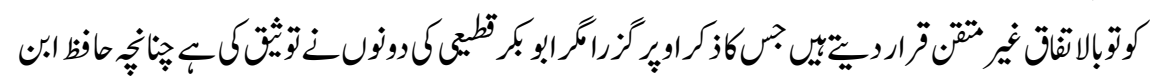

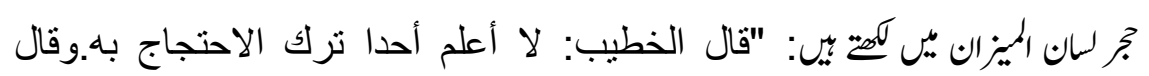

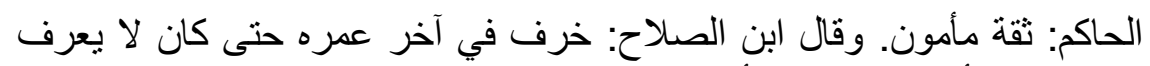

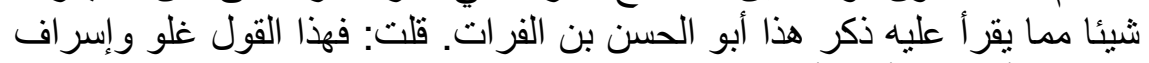

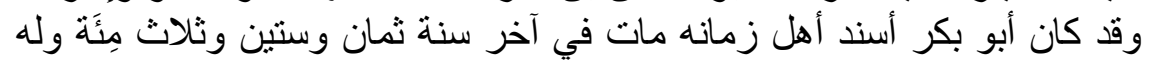
خمس وتسعون سنة".

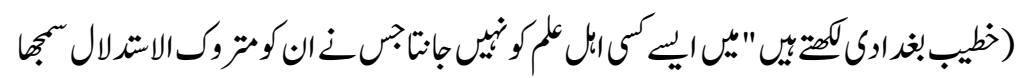

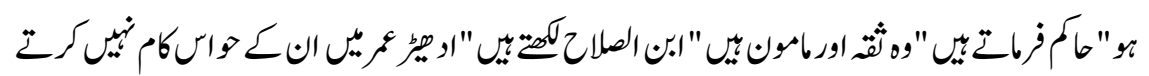

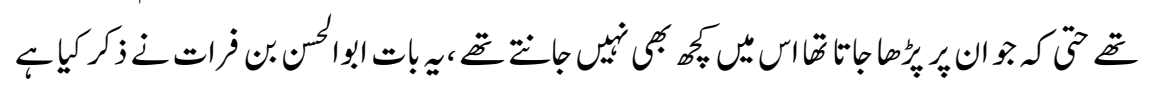

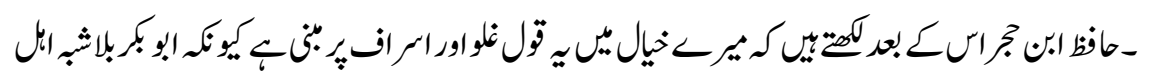

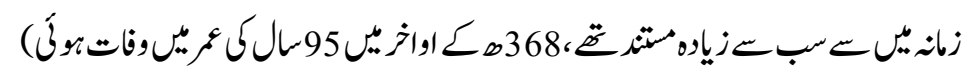




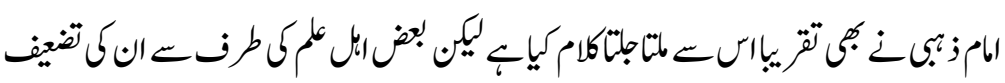

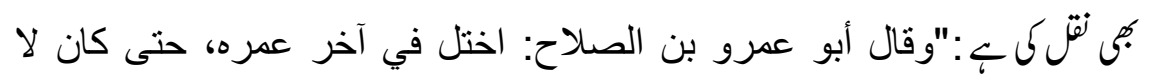

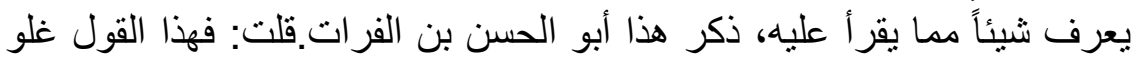

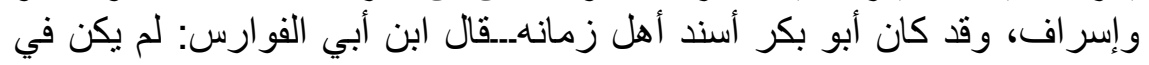

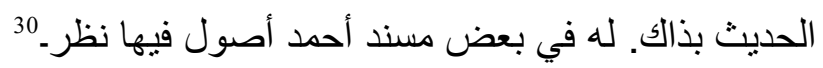

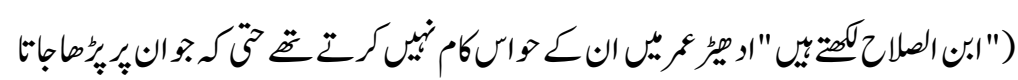

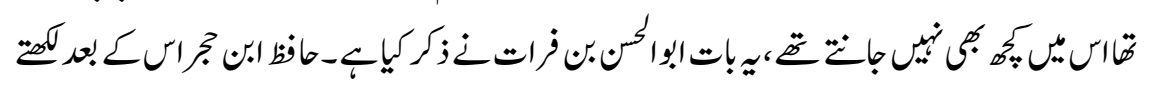

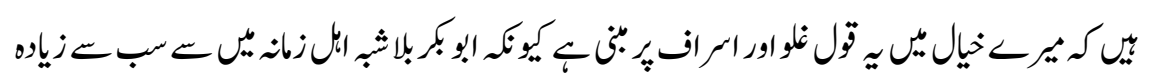

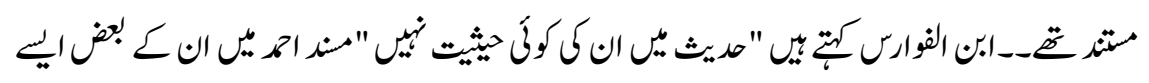

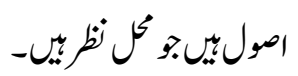

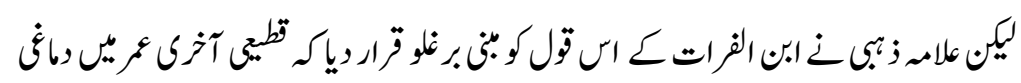

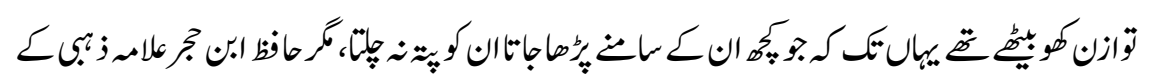

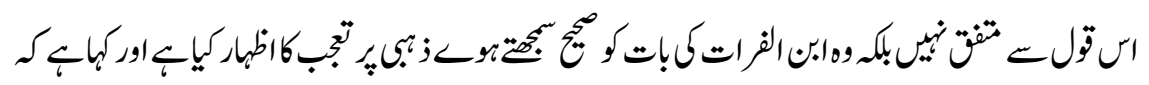

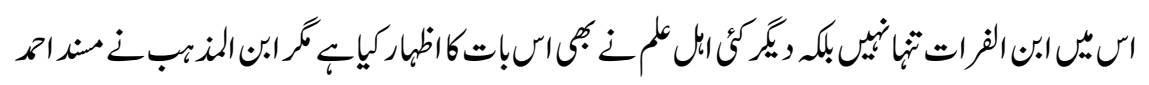

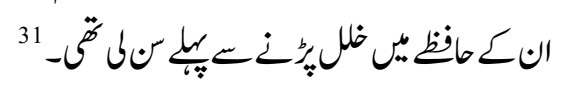

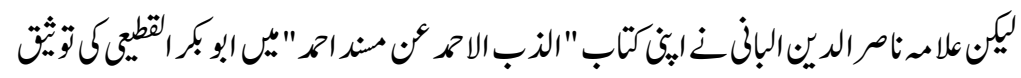

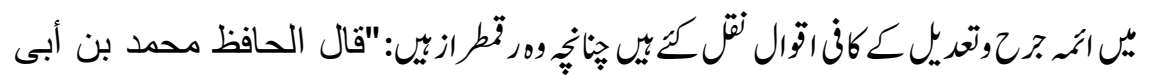

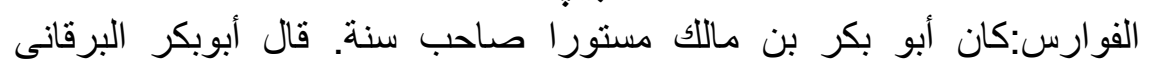

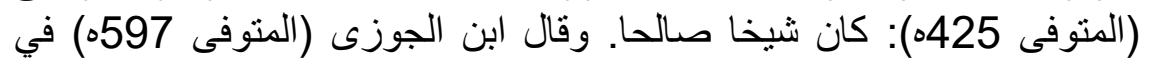

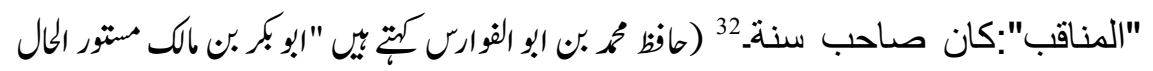

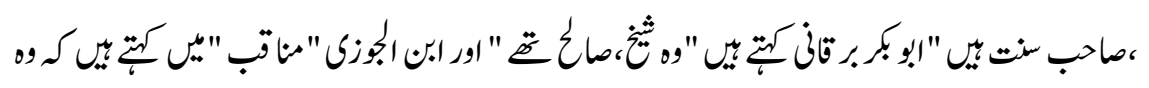

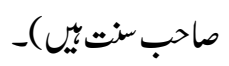




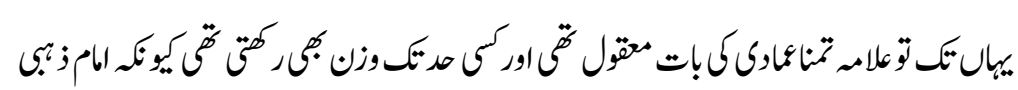

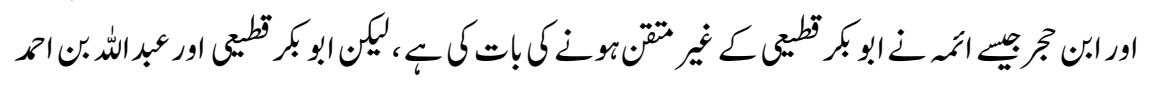

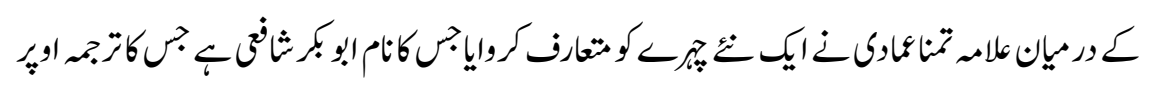

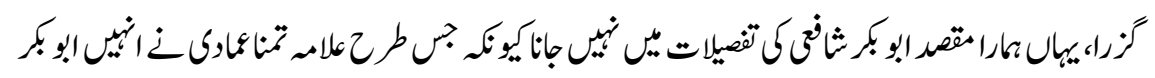

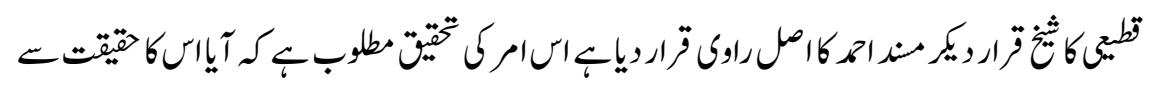

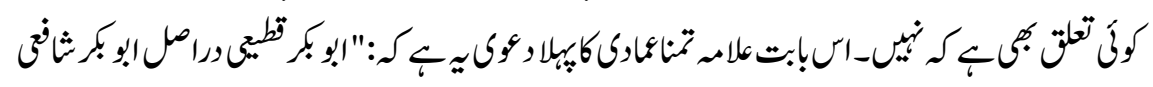

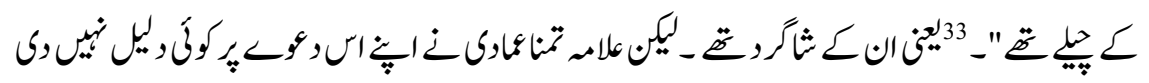

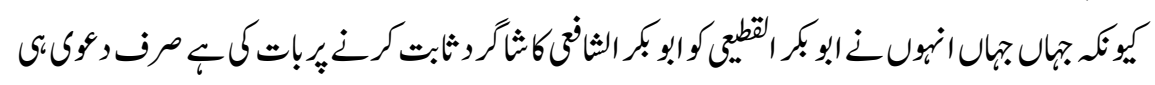

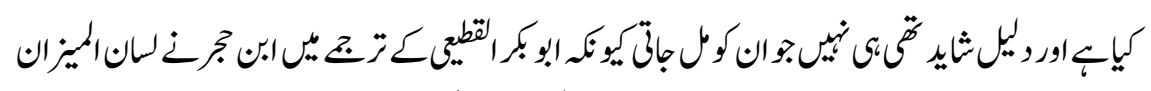

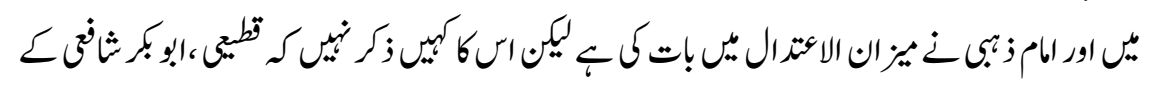

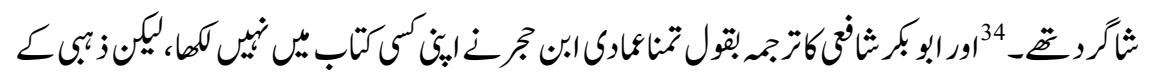

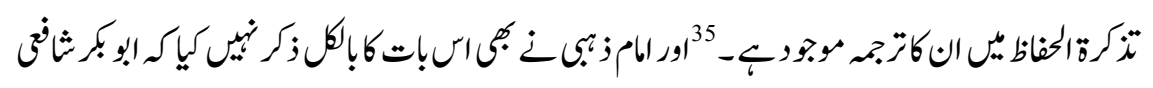

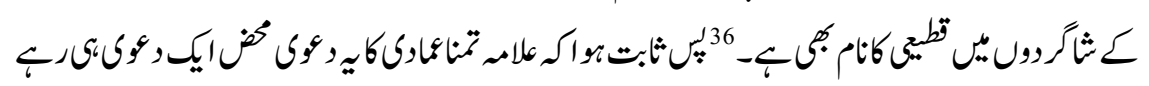

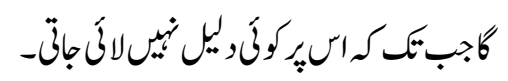

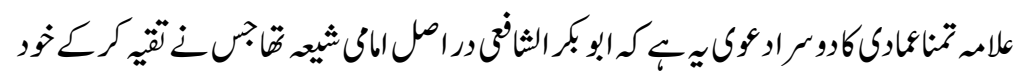

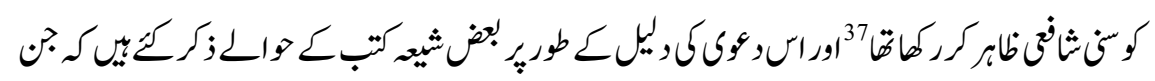

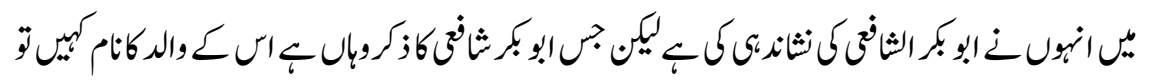

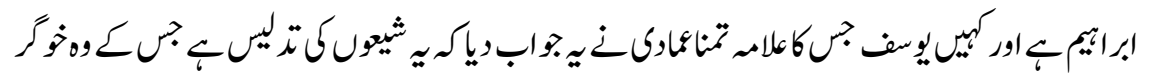

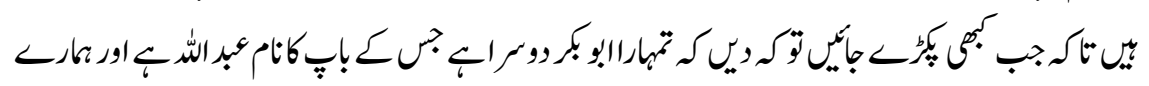

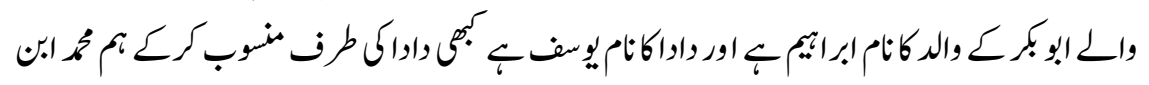

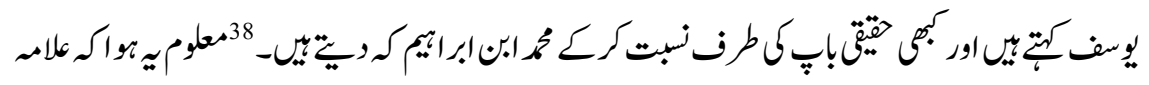

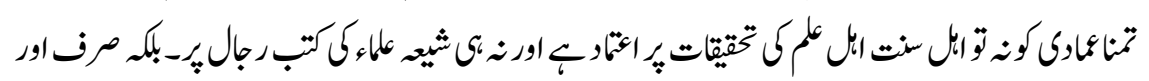

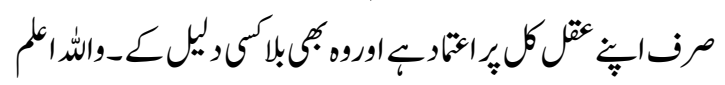




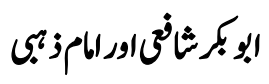

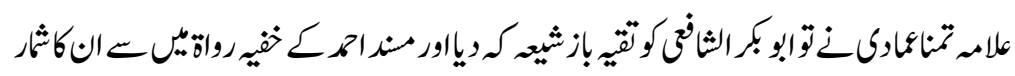

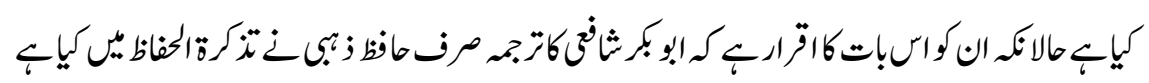

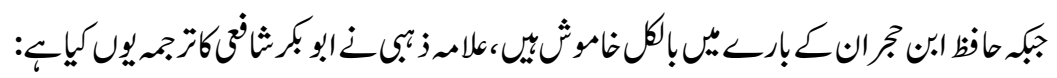

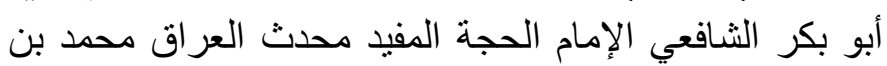

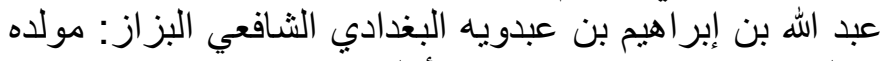
بجبل في سنة ستين ومائتين، وأول سماعه سنة ست الته وسبعين

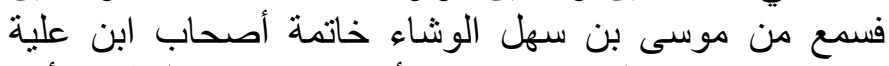

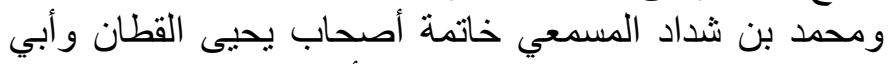

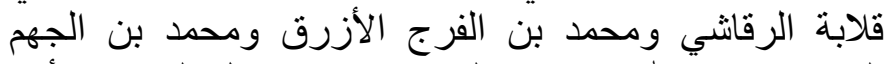

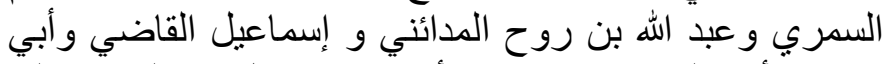
بكر بن أبي الدنيا ومن بعدهم فأكثر، و و ارتحل في الحديث الحيث إلى ألى

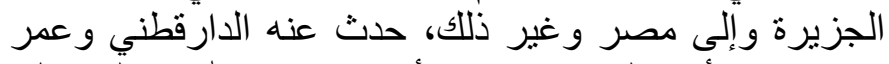

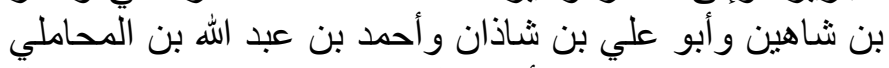

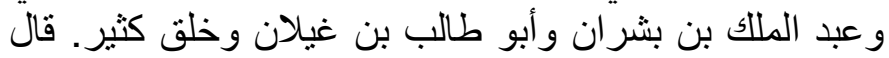
الخطيب: كان نقة ثبنًا حسن التصانيف جمع أبوابًا وشيوخًا،

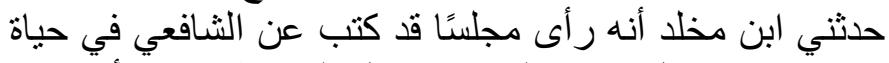

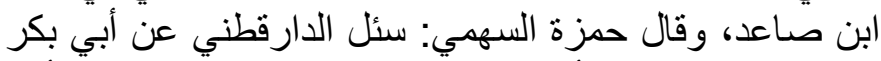

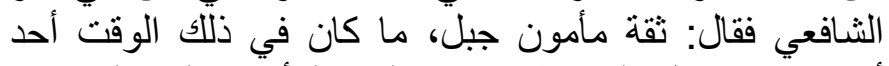

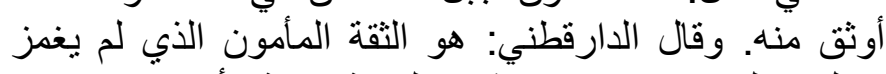
بحال. قلت: مات في ذأني الحجة سنة أربع وخمسين

و مثلاثمائة.

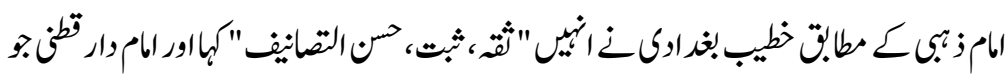

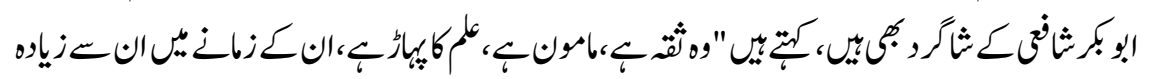

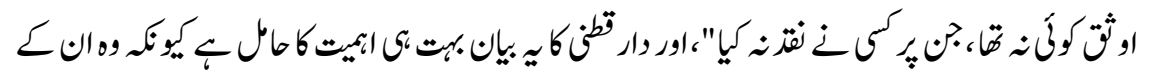

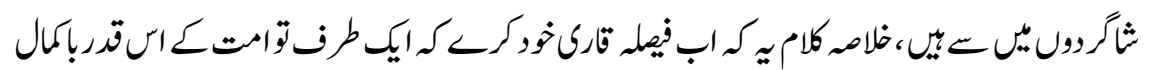

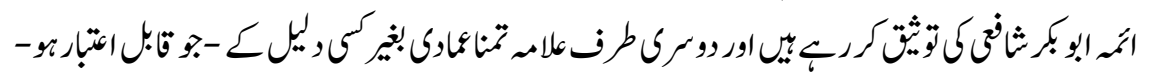

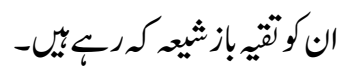




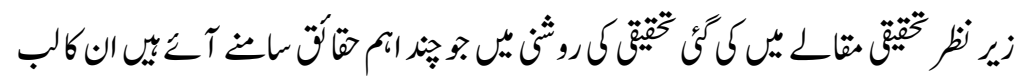

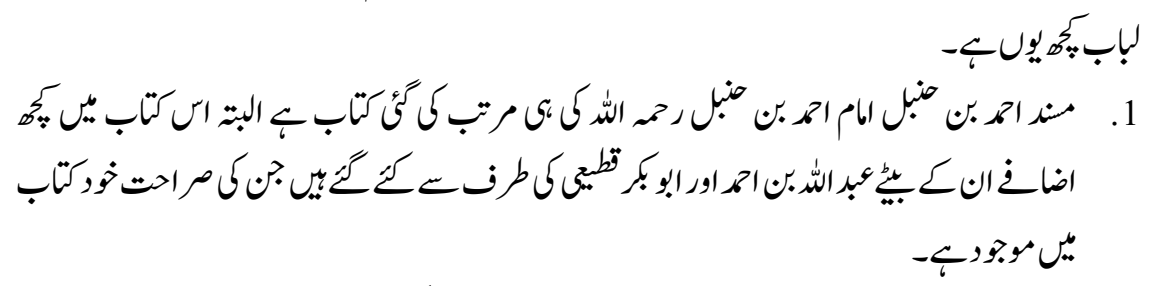

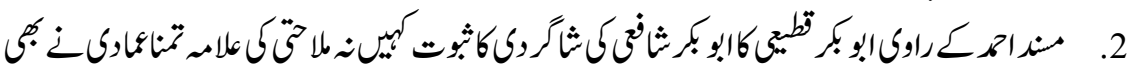

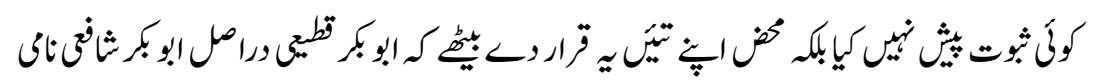

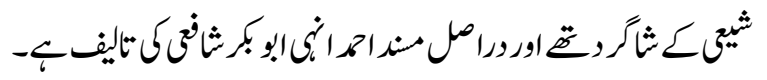

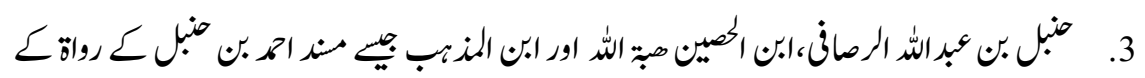

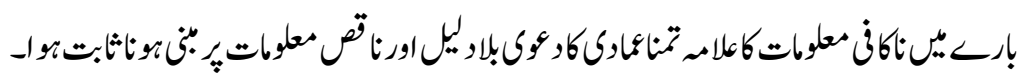

\section{سفارثاتوتجايز}

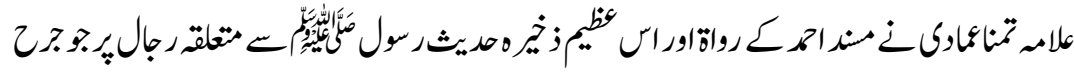

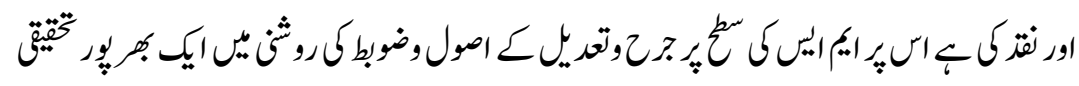

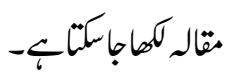

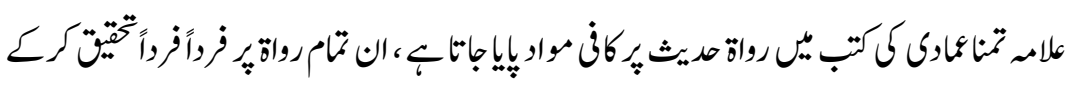

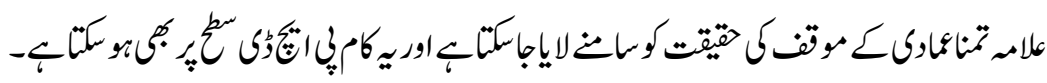

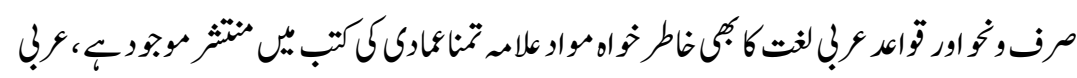

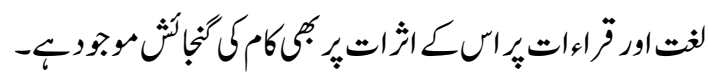

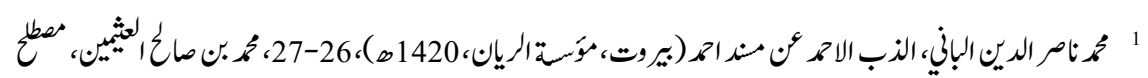

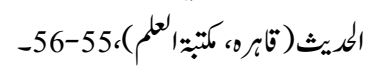

Muhammad Nasir Uddin al-Albani, Az-Zab al-Ahmad an Musnad Ahmad (Berut, Muasasatu Risala al-Rayan, 1420AH, Muhammad bin Saleh al-Usaimeen, Mustalahul Hadith (Cairo, Maktabatul al-Ilm), 55-56.

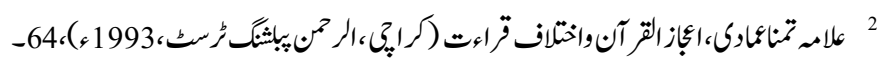


Allama Tamanna Imadi, Aijaz ul Quran wa Ikhtelaf Qeraat (Karachi, Al-Rahman Publshing Trust, 1993), 64.

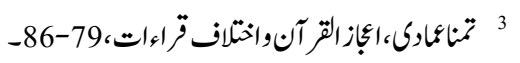

Tamanna Imadi, Aijaz ul Quran wa Ikhtelaf Qeraat, 79-86.

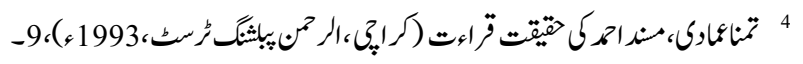

Allama Tamanna Imadi, Musnad Ahmad ki Haqeeqat e Qeraat (Karachi, Al-Rahman Publshing Trust, 1993), 9.

$$
5 \text { تمنائمارك، مندامرك حثيقت تراءت، 11-9- }
$$

Tamanna Imadi, Musnad Ahmad ki Haqeeqat e Qeraat, 9-11.

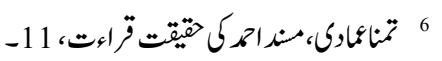

Tamanna Imadi, Musnad Ahmad ki Haqeeqat e Qeraat, 11.

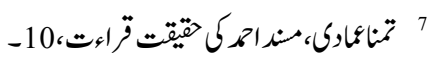

Tamanna Imadi, Musnad Ahmad ki Haqeeqat e Qeraat, 10.

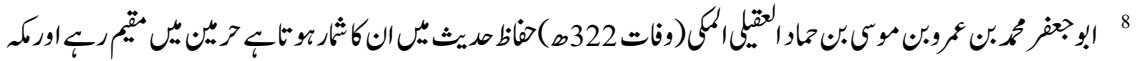

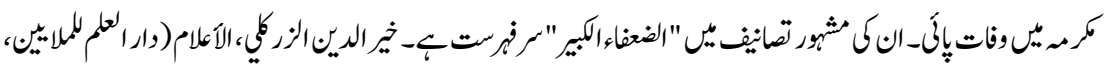

$$
\begin{aligned}
& -319: 6 r(\text { r } 2002
\end{aligned}
$$

Abu Jafar Muhammad bin Amr bin Musa al-Uqaili al-Makki (Died 322AH), He was among Huffaz Hadith, stayed in Haramain, died in Makkah. His famous book is "AlZuafaa al-Kabeer". Khair Uddin al-Zarkali, al-Aalam (Darul Ilm lilmalyeen, 2002), 6: 319.

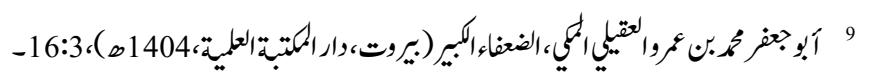

Abu Jafar Muhammad bin Amr bin Musa al-Uqaili, Al-Zuafaa al-Kabeer (Berut, Darul Kutub al-Ilmiyya, 1404AH), 3:16.

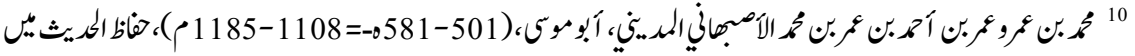

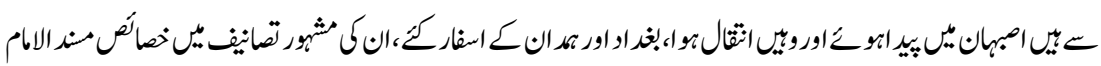

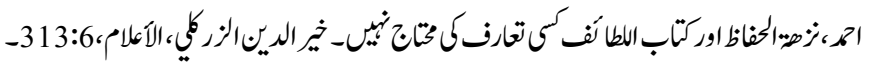

Abu Musa, Muhammad bin Umar bin Ahmad al-Asbahani al-Madini (Died 581AH/ 1185AD), He was Hafiz ul Hadith, born in Asbahan. Among his famous book is: Khasais e Musnad ul al-Imam Ahmad, Nuzhatul Huffaz ... Khair Uddin al-Zarkali, al-Aalam, $6: 313$.

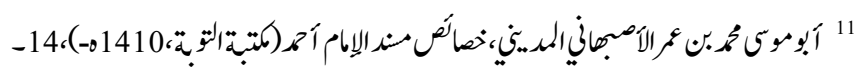

Abu Musa, Muhammad bin Umar al-Asbahani al-Madini (Makatabatu al Tauba, 1410AH), 14.

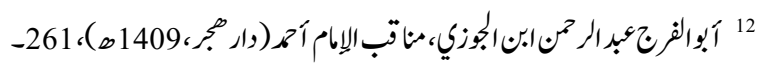

Abul Faraj Abdur Rahman Ibnu al-Jauzi, Manaqib ul Imam Ahmad (Dar Hijr, 1409AH), 14. 
Ibnu al-Jauzi, Manaqib ul Imam Ahmad, 261- 262.

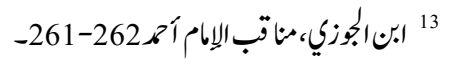

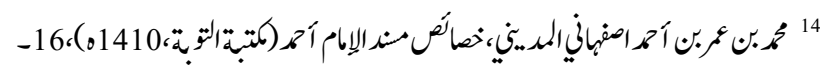

Muhammad bin Umar al-Asbahani al-Madini, 16.

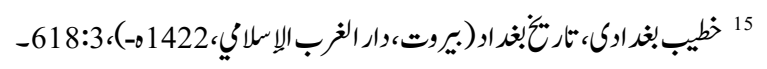

Khateeb Baghdadi, Tarekh Baghdad (Berut, Darul Gharb al-Islami, 1422AH), 3: 618.

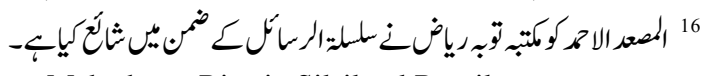

Al-Misaad al-Ahmad published from Maktabatur Riaz in Silsilatul Rasail.

$$
17 \text { تمنائمارك، مند احرك حثيتت،60-61-60-61. }
$$

Tamanna Imadi, Musnad Ahmad ki Haqeeqat e Qeraat, 60-61.

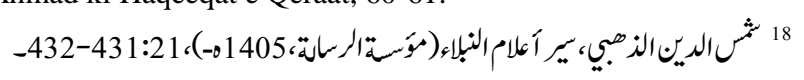

Shamsuddin al-Zahabi, Siyar ul al-Aalam al-Nubalaa (Muasastur Risala, 1405AH), 21: 431-432.

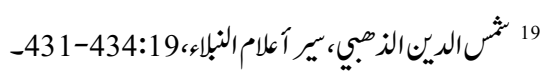

Shamsuddin al-Zahabi, Siyar ul al-Aalam al-Nubalaa, 19: 431- 434.

$$
20
$$

Shamsuddin al-Zahabi, Siyar ul al-Aalam al-Nubalaa, 19: 536-539.

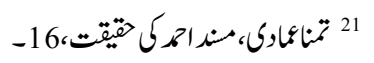

Tamanna Imadi, Musnad Ahmad ki Haqeeqat e Qeraat, 16.

$$
22 \text { تمنائمارك، -نر احمكى خيقت،17- }
$$

Tamanna Imadi, Musnad Ahmad ki Haqeeqat e Qeraat, 17.

$$
23 \text { تمنائمارك، مندراحكى حثيقت،-17-20- }
$$

Tamanna Imadi, Musnad Ahmad ki Haqeeqat e Qeraat, 17- 20.

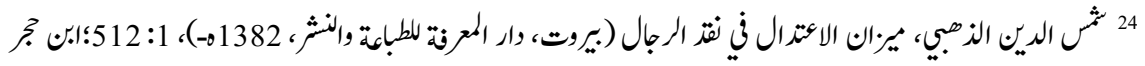

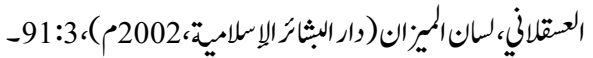

Shamsuddin al-Zahabi, Meezan ul Ietedal fi Naqdir Rijal (Darul Maarifa littibagha wanNashr, 1382 AH), 1: 512, Ibne Hajar al-Asqalani, Lisan ul Meezan (Darul Bashair alIslamia, 2002AD), 3: 91.

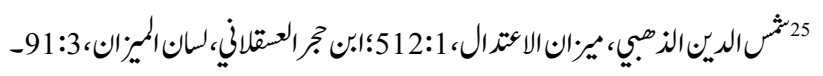

Shamsuddin al-Zahabi, Meezan ul Ietedal, 1: 512, Ibne Hajar al-Asqalani, Lisan ul Meezan, 3: 91.

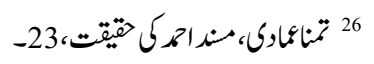

Tamanna Imadi, Musnad Ahmad ki Haqeeqat e Qeraat, 23.

$$
27 \text { تمنائمارى، مندامكى ثيقت،26-27- }
$$

Tamanna Imadi, Musnad Ahmad ki Haqeeqat e Qeraat, 26-27. 


$$
28 \text { تمنائمارك، سنر احمك قتيقت،42- }
$$

Tamanna Imadi, Musnad Ahmad ki Haqeeqat e Qeraat, 42.

$$
29 \text { ابن ججرالعقلاني، لانا الميمّان، 418:1- }
$$

Ibne Hajar al-Asqalani, Lisan ul Meezan, 1: 418.

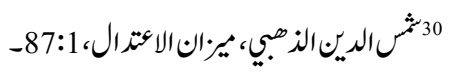

Shamsuddin al-Zahabi, Meezan ul Ietedal, 1: 87.

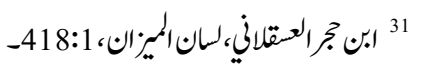

Ibne Hajar al-Asqalani, Lisan ul Meezan, 1: 418.

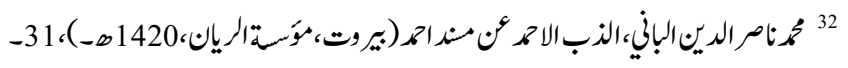

Nasir Uddin al-Albani, Az-Zab al-Ahmad an Musnad Ahmad, 31.

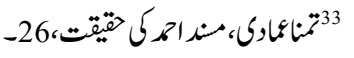

Tamanna Imadi, Musnad Ahmad ki Haqeeqat e Qeraat, 26.

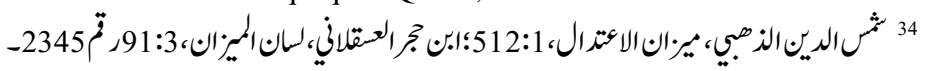

Shamsuddin al-Zahabi, Meezan ul Ietedal, 1: 512, Ibne Hajar al-Asqalani, Lisan ul Meezan, 1: 91.

$$
35 \text { تمنائمارك، مند اكرك قيقتت،32-33- }
$$

Tamanna Imadi, Musnad Ahmad ki Haqeeqat e Qeraat, 32-33.

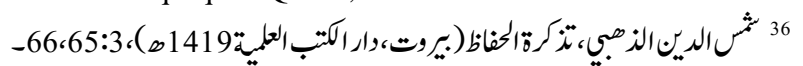

Shamsuddin al-Zahabi, Tazkiratul Huffaz (Berut, Darul Kutub al-Ilmiyya, 1419AH), 3: 65-66.

$$
37 \text { تمنائمارك، مند اكرك قيقتت،35-36- }
$$

Tamanna Imadi, Musnad Ahmad ki Haqeeqat e Qeraat, 35-36.

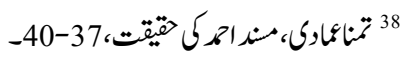

Tamanna Imadi, Musnad Ahmad ki Haqeeqat e Qeraat, 37-40.

Shamsuddin al-Zahabi, Tazkiratul Huffaz, 3: 65.

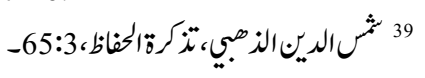

